\title{
Nanotechnology-based drug delivery systems for treatment of oral cancer: a review
}

\author{
This article was published in the following Dove Press journal: \\ International Journal of Nanomedicine \\ 8 August 2014 \\ Number of times this article has been viewed
}

\author{
Giovana Calixto \\ Jéssica Bernegossi \\ Bruno Fonseca-Santos \\ Marlus Chorilli \\ School of Pharmaceutical Sciences, \\ Department of Drugs and \\ Pharmaceuticals, São Paulo State \\ University (UNESP), São Paulo, Brazil
}

Correspondence: Giovana Calixto/ Marlus Chorilli

School of Pharmaceutical Sciences, Department of Drugs and Pharmaceuticals, São Paulo State University (UNESP), Rodovia AraraquaraJaú Km 0I, Araraquara, São Paulo, Brazil, | $480 \mid-902$

Tel +551633016961

Fax +551633220073

Email calixtogmf@fcfar.unesp.br/ chorilli@fcfar.unesp.br

\begin{abstract}
Oral cancer (oral cavity and oropharynx) is a common and aggressive cancer that invades local tissue, can cause metastasis, and has a high mortality rate. Conventional treatment strategies, such as surgery and chemoradiotherapy, have improved over the past few decades; however, they remain far from optimal. Currently, cancer research is focused on improving cancer diagnosis and treatment methods (oral cavity and oropharynx) nanotechnology, which involves the design, characterization, production, and application of nanoscale drug delivery systems. In medicine, nanotechnologies, such as polymeric nanoparticles, solid lipid nanoparticles, nanostructured lipid carriers, gold nanoparticles, hydrogels, cyclodextrin complexes, and liquid crystals, are promising tools for diagnostic probes and therapeutic devices. The objective of this study is to present a systematic review of nanotechnology-based drug delivery systems for oral cancers.
\end{abstract}

Keywords: targeted delivery, oral squamous cell carcinoma, oral cancer treatment

\section{Introduction}

Oral squamous cell carcinoma (OSCC) is the sixth most common cancer for both sexes worldwide, and the 5-year survival rate for this disease is approximately $50 \%{ }^{1}$ In 2011, OSCC accounted for nearly 3\% of all cancer cases worldwide; its estimated incidence is approximately 275,000 cases per year, with two-thirds of these cases occurring in developing countries. ${ }^{1}$ In 2013, there were 41,380 estimated new cases of oral cavity and pharyngeal cancer in the US for both sexes, with $32.8 \%$ associated with the tongue, $27.5 \%$ with the mouth, $33.7 \%$ with the pharynx, and $5.9 \%$ in other parts of the oral cavity. There were also 7,890 estimated deaths in the US, of which an estimated $19.1 \%$ were new cases, with $26.2 \%$ associated with the tongue, $22.8 \%$ with the mouth, $30.4 \%$ with the pharynx, and $20.8 \%$ in other parts of the oral cavity. ${ }^{2}$ OSCC is a malignant tumor of the squamous epithelium lining the oral mucosa. These tumors are malignant and tend to spread rapidly. The main causes of oral cancer include excessive alcohol intake and tobacco use. ${ }^{3-5}$ Exposure to sunlight is a causative factor for cancer of the lips, which is similar to that for skin cancer. ${ }^{6-9}$ Human papilloma virus is also a risk factor for causing oral cancer. ${ }^{10-13}$ Immunosuppressed patients (eg, human immunodeficiency virus [HIV] and renal transplant patients) have the highest risk factor for developing oral cancer. ${ }^{14,15}$

The prevalence has shown a 5.3-fold increase for men and a twofold increase for women over the past 2 decades. ${ }^{16}$ In addition, the annual death toll for oral cancer in males has been rapidly increasing. ${ }^{17}$ The 5 -year mortality rate for oral cancer is approximately $50 \%$ worldwide,${ }^{18-20}$ which signifies a poor prognosis for developing countries. ${ }^{1}$ The rates for OSCC recurrence vary from $18 \%$ to $76 \%$ for patients who undergo standard treatment, and a delay in starting treatment is considered the major cause for no relevant improvement in the survival rate. ${ }^{21}$ 
Diagnostic confirmation is only possible by biopsy and histopathological analysis prior to treatment ${ }^{22-28}$ with possible prior cytological evidence, ${ }^{29-31}$ and lengthy and expensive diagnostic investigations that only delay the initiation of treatment should be avoided. Nevertheless, the delay in the diagnosis of oral cancer has resulted in increasing the time to treatment initiation and a consequent decrease in the survival rate of patients. ${ }^{1}$

To increase the effectiveness of treatment and reduce side effects, the incorporation of nanotechnology-based drug delivery systems, such as polymeric nanoparticles (PNPs), solid lipid nanoparticles (SLNs), nanostructured lipid carriers (NLCs), gold nanoparticles, hydrogels, cyclodextrin complexes, and liquid crystals (LCs), represents an interesting option for drug delivery, as demonstrated in Table 1.

\section{Pathophysiology of oral cancer}

The genomic pathway plays a role in OSCC, whereby alterations in the genome result in the altered expression of proteins, chemical mediators, and enzymes. ${ }^{32}$ Carcinogenesis is a process with multiple steps, each characterized by the sequential stimulation of additional genetic defects followed by clonal expansion. Due to oncogene activation and tumor suppressor gene inactivation, OSCC leads to the deregulation of cell proliferation and death. The genetic alterations include gene amplification, oncogene overexpression, mutations, deletions, and hypermethylation, leading to the inactivation of particular genes such as the $p 53$ tumor suppressor gene. ${ }^{33}$

Oncogenes do not play an important role in the cancer process, although they do play a role in initiation. Initiation transforms a normal cell into a premalignant cell, and it requires the inactivation of negative regulators in the cell (eg, tumor suppressor genes), which is considered an important event that leads to the development of malignancy. Tumor suppressor genes are most often inactivated by point mutations, deletions, and rearrangements in both gene copies..$^{34,35}$

Mutations in $p 53$ and $p 16$ are involved in the carcinogenesis process. The $p 53$ gene plays a role in maintaining genomic stability, cell cycle progression, cellular differentiation, DNA repair, and apoptosis, and $p 16$ is involved in cell cycle regulation, including cell cycle arrest and apoptosis. ${ }^{36}$

The tumor suppressor gene $p 53$ is known to be mutated in approximately $70 \%$ of all adult solid tumors. ${ }^{37}$ These p53 gene mutations have been associated with smoking and the use of tobacco in squamous cell carcinomas of the head and neck. ${ }^{38}$ An in vivo study of functionally inactivated $p 53$ in

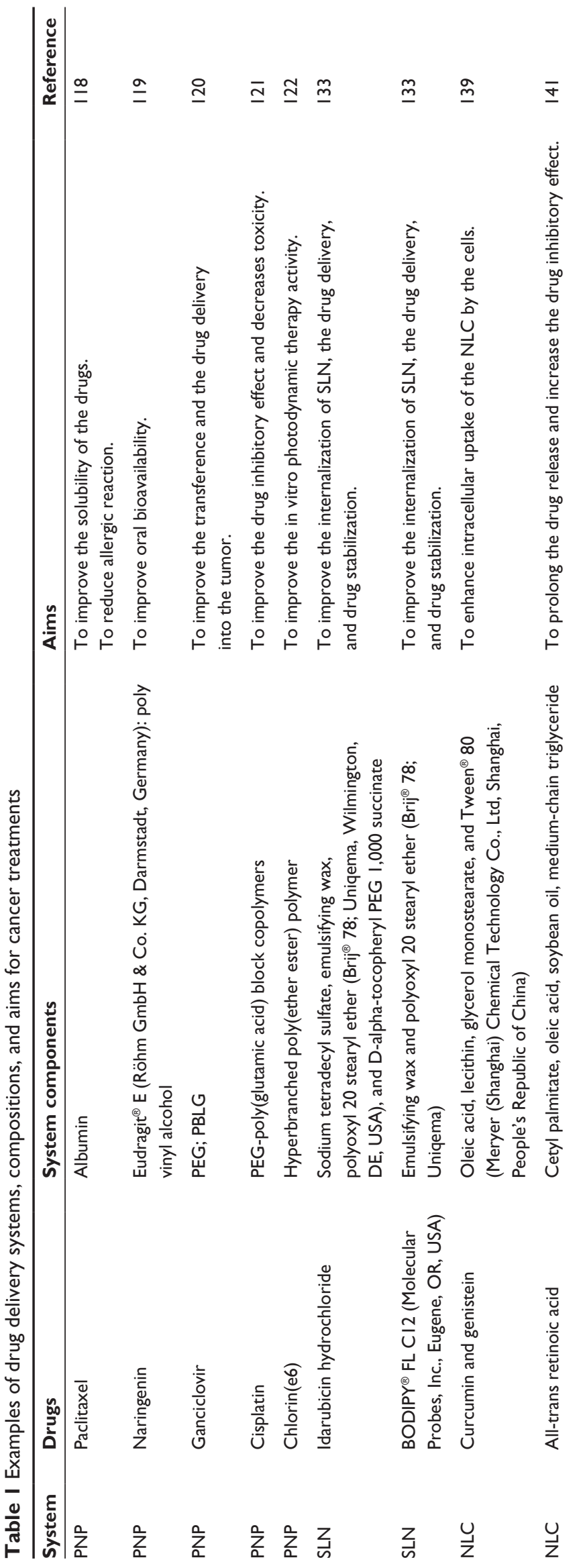




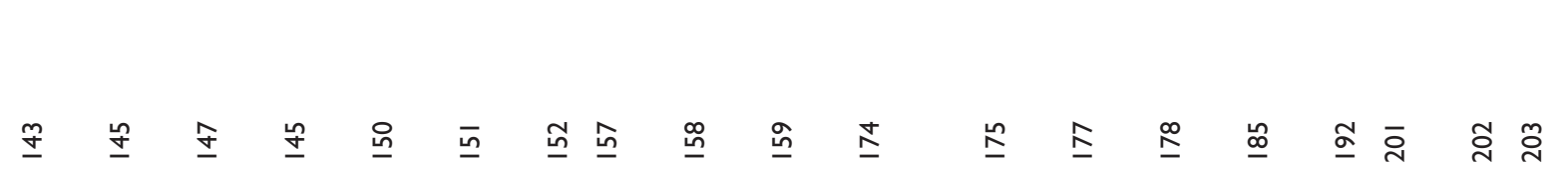
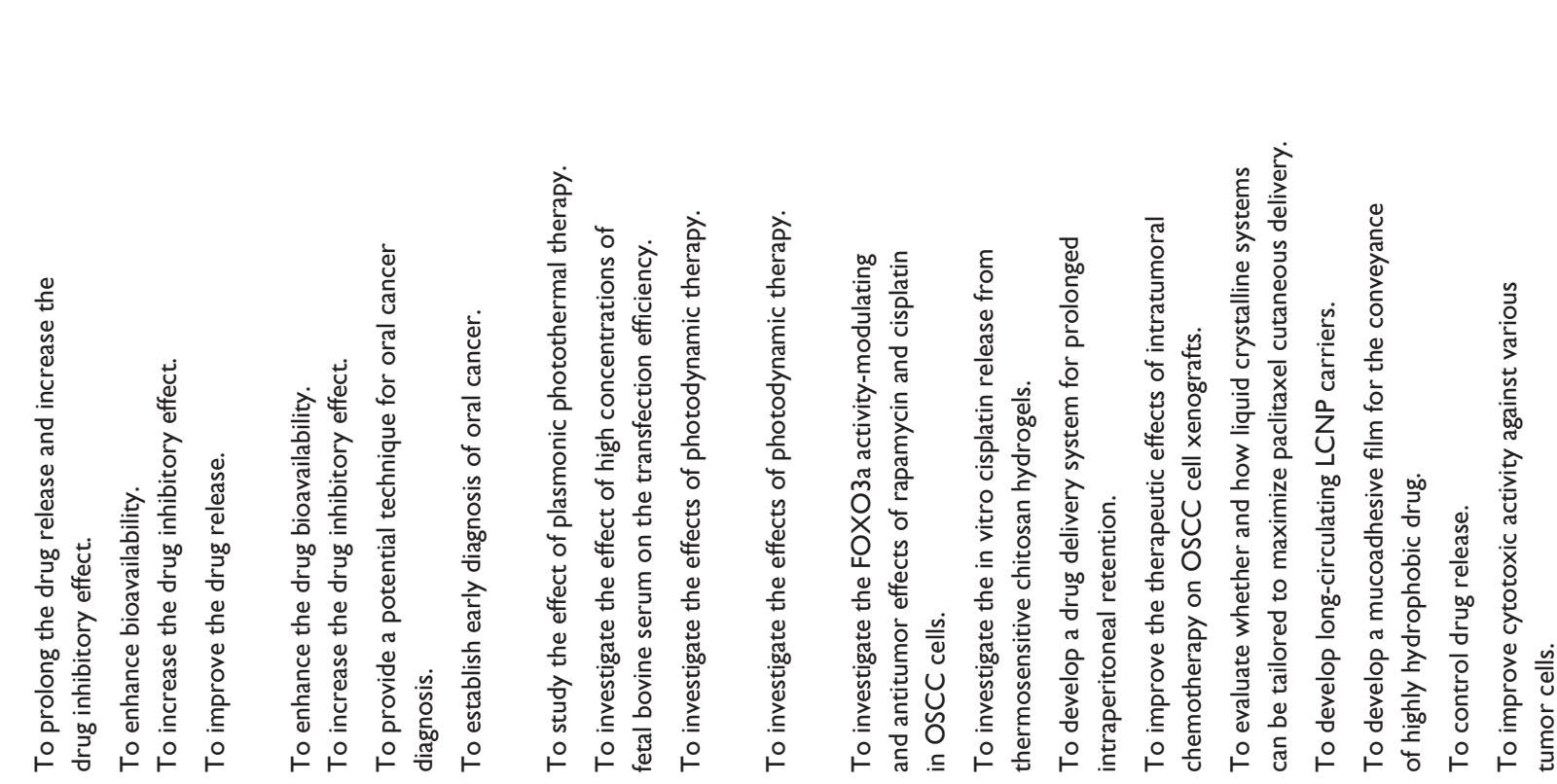

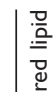

(u)

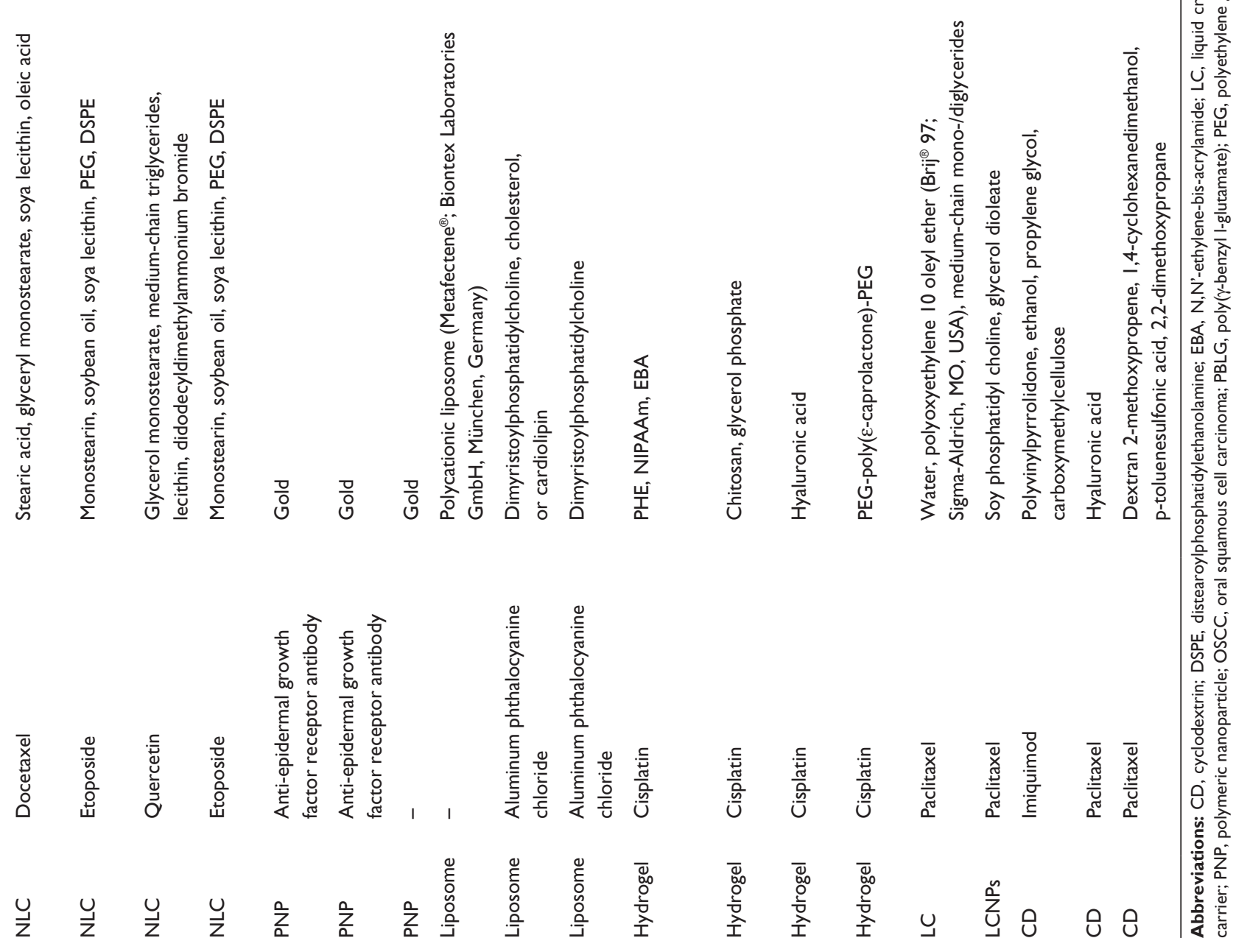


oral tumors and the restoration of $p 53$ in oral cancer lines and tumors induced in animal models demonstrated reversal of the malignant phenotype. ${ }^{39}$

Another OSCC characteristic is telomerase activity. Several oral tumors have been confirmed to have the expression of telomerase, which is strongly associated with malignancy in oral tissues. Telomerase activity has been identified in OSCC, with $80 \%$ of patients with head and neck squamous cell carcinoma ${ }^{40}$ having telomerase activity, and it has been reported that most immortal OSCC cell lines have high levels of telomerase and have tumor radioresistance. ${ }^{41,42}$

Other chemical mediators are involved in oral cancer pain, such as endothelin-1 (ET-1), proteases, and nerve growth factor. ${ }^{43}$ ET-1 is a potent vasoactive peptide that produces nociception. In oral cancer, ET-1 binds to the endothelin-B receptor and is expressed on nonmyelinating Schwann and dorsal root ganglion satellite cells. ${ }^{44}$ In patients with OSCC, the ET-1 levels are higher in the tumor microenvironment, and nociception was reported with mechanical stimuli parallel to the mechanical allodynia. ${ }^{45,46}$ The role of ET-1 in oral cancer pain was confirmed and characterized in a mouse model by Pickering et $\mathrm{al}^{47}$ and the ET- 1 concentration was a more important factor than tumor volume in establishing cancer pain.

Protease-activated receptor type $2\left(\mathrm{PAR}_{2}\right)$ is involved in oral cancer. ${ }^{48,49}$ This receptor is activated by serine proteases, trypsin, and tryptase. ${ }^{50} \mathrm{PAR}_{2}$ activates dual messenger pathways in a second step that sensitizes transient receptor potential vanilloid type-1 $\left(\mathrm{TRPV}_{1}\right)$ and transient receptor potential vanilloid type-4 $\left(\mathrm{TRPV}_{4}\right)$ receptors on nociceptive afferents where there is resulting $\mathrm{TRPV}_{1}$-dependent thermal hyperalgesia and $\mathrm{TRPV}_{4}$-dependent mechanical allodynia. ${ }^{51}$ In OSCC, the fibroblasts in the stroma produce trypsin, and this serine protease is capable of activating $\mathrm{PAR}_{2}$ on sensory neurons. This continual release of serine proteases in the microenvironment could produce an ongoing excitation of primary nociceptive afferents, leading to mechanical allodynia in oral cancer patients. ${ }^{49}$

In the microenvironment of many cancers, sensory neurons are chronically exposed to nerve growth factor (NGF). ${ }^{1,52}$ The acute peripheral administration of this chemical mediator leads to thermal hyperalgesia, whereas chronic administration produces mechanical allodynia. ${ }^{53}$ The activity of NGF is mediated via a receptor tyrosine kinase, ${ }^{.4}$ thus, NGF can also facilitate the proliferation and invasion of multiple cancers, ${ }^{55,56}$ including oral cancer; ${ }^{56}$ a process related to pain. The pain mechanism in oral cancer can be established by association with perineural involvement, with invasion and proliferation of a cancer occurring within a nerve associated with pain. ${ }^{56,57}$ Higher NGF levels were found in cancer tissues from oral cancer patients. ${ }^{57}$

Angiogenesis is a crucial step in the processes of uncontrolled tumor proliferation and metastasis, and inhibiting angiogenesis is considered to be effective for treating oral cancer. Vascular endothelial growth factor (VEGF) is thought to be an important angiogenic factor, ${ }^{58}$ and studies have shown that OSCC is associated with an elevated VEGF concentration in the serum. These higher levels of VEGF are correlated with lymph node metastasis, clinical stage, and the prognosis and treatment of OSCC. ${ }^{59-62}$

Cancer cells induce the development of an exaggerated inflammatory state in the stroma, which in turn promotes cancer growth, invasion, and metastasis. Inflammatory cells in the microenvironment, such as myeloid dendritic cells, macrophage subtypes (M1 and M2), mast cells, neutrophils, and $\mathrm{T}$ and B lymphocytes, secrete chemokines, prostaglandins, proteinases, and complement components that collectively adopt an exaggerated inflammatory state that promotes cancer growth, tissue invasion, and metastasis. ${ }^{63-65}$

The chemical mediators produced by an upregulation in inflammation include transforming growth factor beta (TGF- $\beta$ ), tumor necrosis factor alpha (TNF- $\alpha$ ), interleukin (IL)-6, cyclooxygenase 2 (COX-2), and matrix metalloproteinase-7 (MMP-7). ${ }^{66,67}$ TNF- $\alpha$ and IL-6 are produced by malignant keratinocytes, stromal fibroblasts, and macrophages, and these cytokines promote tumor growth by modifying the expression of cell-adhesion molecules and extracellular matrix proteins and stimulate angiogenesis. ${ }^{68}$

A high level of COX-2 expression exists in stromal cells and cancerous cells at the invasive front in OSCC. ${ }^{69,70}$ Thus, COX-2 plays a role in the process of local invasion and metastasis. ${ }^{62}$ Increased COX-2 expression in OSCC is associated with a high rate of recurrence after treatment with a poor response to radiotherapy and poor prognosis. ${ }^{71}$ Matrix metalloproteinases are involved in the cell migration, angiogenesis, and proteolytic activation of growth factors, events necessary for invasion into surrounding connective tissue for neoplastic cells. ${ }^{72,73}$ MMP-7 plays a pivotal role in inflammatory diseases and malignant invasion by tissue remodeling ${ }^{72,74}$ and destroying the extracellular matrix, including the basement membrane, and this process is necessary for invasion and metastasis. ${ }^{75}$ Increased MMP-7 expression has been found to be related to oral cancer. ${ }^{72,76}$

Nuclear factor-kappa B (NF- $\mathrm{KB})$ participates in the expression of genes involved in inflammatory and immune responses, cell proliferation, and survival. ${ }^{77} \mathrm{NF}-\kappa \mathrm{B}$ protein levels gradually increase from the premalignant lesion stage to invasive cancer, indicating an important role for $\mathrm{NF}-\kappa \mathrm{B}$ 
in the early stages of carcinogenesis. ${ }^{77,78}$ In OSCC, reduction in NF- $\kappa \mathrm{B}$ activity results in low IL levels, including those for IL-2, IL-6, and IL-8. In addition, IL-8 plays a role in the induction of the angiogenesis process. ${ }^{79}$

A number of complex mechanisms are involved in the genesis and progression of oral cancer. OSSC is a multistep process in which multiple genetic events occur that alter the normal function of oncogenes and tumor suppressor genes. These events can result in the increased production of growth factors. Recent advances in the understanding of the molecular control of these various pathways will allow for more accurate diagnosis and assessment of prognosis and might lead the way for more novel approaches for treatment and prevention.

\section{Oral cancer treatment}

Treatment protocols for oral cavity cancers are generalized therapies based on stage, chemoradiation therapy, and induction chemotherapy for locally advanced disease. ${ }^{28,80}$ In current therapies, some anticancer drugs have been used alone or in combination for the treatment of oral cancer, such as cisplatin, cetuximab, fluorouracil, paclitaxel, docetaxel (DTX), and methotrexate. ${ }^{81-90}$

The oral administration of anticancer agents is preferred by patients for its convenience and potential for outpatient treatment. In addition, oral administration facilitates prolonged exposure to a cytotoxic agent. ${ }^{91}$ However, low solubility in aqueous fluids, low apparent permeability, and poor bioavailability are noted as limitations for oral chemotherapy. ${ }^{92,93}$ Intravenous administration is the most direct, and it overcomes the variable absorption patterns of the gastrointestinal tract. Intravenous administration leads to immediate and complete bioavailability; thus, this route has the potential to be hazardous because high concentrations of drugs are delivered to normal tissues, causing greater damage to healthy tissues and increased adverse reactions. ${ }^{94}$

To overcome the disadvantages of current cancer treatment techniques, the scientific community has turned toward nanotechnology to develop new and more effective nanotechnology-based drug carrier systems to optimize oral, buccal, and intravenous treatment routes.

\section{Nanotechnology-based drug delivery systems Nanoparticles}

Nanoparticles can be defined as ultradispersed solid supramolecular structures with a submicrometer size ranging from 10 to $1,000 \mu \mathrm{m} .{ }^{95-97}$ The drugs can be dissolved, entrapped, encapsulated, or attached to a nanoparticle matrix, which acts as a reservoir for particulate systems and therefore plays an important role as a drug delivery system for clinical applications, particularly in oncology..$^{98,99}$

Nanoparticles fabricated from polysaccharides, proteins, and biocompatible/biodegradable polymers, such as polyethylene glycol (PEG), poly( $\gamma$-benzyl l-glutamate) (PBLG), poly(D,L-lactide), poly(lactic acid) (PLA), poly(D,L-glycolide), poly(lactide-co-glycolide), polycyanoacrylate, chitosan, gelatin, and sodium alginate are called PNPs. ${ }^{96,100-107}$

The nanoparticles (NPs) are mainly prepared via the dispersion of preformed polymers, the polymerization of monomers, ionic gelation, or the coacervation of hydrophilic polymers, but other methods for their generation have also been reported, such as supercritical fluid technology and particle replication in non-wetting templates $\left(\mathrm{PRINT}^{\circledR}\right.$; DeSimone Lab, Chapel Hill, NC, USA). ${ }^{108-114}$

NPs can improve the stability of drugs and control their targeted delivery, allowing for a constant and uniform concentration at the site of a lesion and facilitating drug extravasation into the tumor system, thus reducing side effects. ${ }^{115-117}$

Damascelli et al evaluated the effectiveness of the intraarterial infusion of paclitaxel incorporated in NPs based on human albumin (albumin NPs) for use as induction chemotherapy before definitive advanced tongue cancer treatment. ${ }^{118}$ Paclitaxel is a lipophilic drug; therefore, surface-active agents must be added for dissolution in organic fluids. In addition, paclitaxel causes severe allergic reactions with intravenous use. Albumin NPs are attractive formulations because they can incorporate a significant amount of drugs into a particle matrix due to the different drug-binding sites present in albumin molecules. Damascelli et al reported that the intra-arterial infusion of paclitaxel in albumin nanoparticles is reproducible and effective. ${ }^{118}$

Sulfikkarali et al investigated the anti-buccal tumor effects of naringenin (NAR)-loaded nanoparticles (NARNPs) prepared in a NAR:aminoalkyl methacrylate copolymers Eudragit $^{\circledR}$ (Röhm GmbH \& Co. KG, Darmstadt, Germany) E:poly vinyl alcohol (1:10:10; weight $(\mathrm{w}) / \mathrm{w} / \mathrm{w})$ ratio by a nanoprecipitation method. ${ }^{119}$ NAR has promising pharmacological activity; however, it has low oral bioavailability, which is a crucial obstacle. The results of the study revealed that NARNPs have more potent antitumor effects than free NAR, preventing the formation of OSCC. In addition, NARNPs improved the biochemical status to a normal range in 7,12-dimethylbenz(a)anthracene-induced oral carcinogenesis. This result may be attributed to the fact that NAR nanoparticulates can arrive at tumor sites via a process called "enhanced permeation and retention" due to the fact that the tumor tissue vasculature is porous with leaky endothelium, 
which increases and sustains the drug concentration inside tumor cells over time, leading to higher antitumor efficacy compared with free NAR. ${ }^{119}$

Yu et al also investigated the action of NPs against oral cancer. These authors assessed the anticancer effects of herpes simplex virus thymidine kinase (HSV-TK)-loaded PEGPBLG nanoparticles and PEG-PBLG nanoparticle-mediated HSV-TK/ganciclovir nanoparticles toward OSCC. ${ }^{120} \mathrm{HSV}-\mathrm{TK}$ is a good apoptosis-inducing gene; however, its transference into the tumor is critical. However, the results demonstrated that HSV-TK-loaded PEG-PBLG nanoparticles had a coreshell structure, DNA protection, and higher gene-transfer efficiency and released DNA gradually; thus, they can be used as gene carriers in future clinical applications. Furthermore, PEG-PBLG nanoparticle-mediated HSV-TK/ganciclovir had a strong anticancer effect on buccal carcinoma induced in golden hamsters. ${ }^{120}$

In another study, ${ }^{121}$ the potential antitumor activity of cisplatin-loaded nanoparticles based on PEG-poly(glutamic acid) block copolymers was assayed in four OSCCs. The results showed that the growth inhibitory effects of cisplatinloaded nanoparticles were significantly less than that for free cisplatin. However, the caspase- 3 and -7 cascades, which are activated by a cisplatin stimulus, induced the release of cytochrome c from mitochondria and led to an irreversible commitment to apoptotic cell death in both cisplatin- and NC-6004-treated OSC-19 cells. Other interesting data obtained from this study revealed that nephrotoxicity, a crucial side effect of cisplatin-loaded nanoparticles, is much lower than that for free cisplatin. Therefore, it can be interpreted that these NPs are as efficient against OSCC as free cisplatin but with much less renal toxicity. ${ }^{121}$

Li et al prepared NPs based on biocompatible and biodegradable hyperbranched poly(ether ester) polymers that possess many hydroxyl and carboxyl functional groups available for functionalization, including the covalent attachment of drug molecules. ${ }^{122}$ These hyperbranched poly(ether ester) NPs were attached to the photosensitizer chlorin(e6) (ce6), and they demonstrated an improvement in the in vitro photodynamic therapy activity over free ce 6 in CAL 27 human oral cancer cells, which may be due to factors including increased cellular uptake of the photosensitizer and the disaggregating effect of covalently binding ce6 to a hydrophilic polymer that improve the quantum yield of the reactive oxygen species produced during photodynamic therapy. In addition, photosensitizer-loaded nanoparticles can reach the most sensitive subcellular sites, demonstrating a capability for treating superficial oral cancer or precancerous lesions. ${ }^{122}$
Nevertheless, some studies revealed that some of the aforementioned polymers may lead to cytotoxicity after internalization into cells, restricting the use of NPs as a drug delivery system. In addition, the large-scale production of PNPs is also problematic and is not relevant for the pharmaceutical market. ${ }^{123-125}$

Therefore, SLNs were developed to overcome the disadvantages of PNPs because they demonstrate physical stability, protection of incorporated labile drugs from degradation, controlled release, and excellent tolerability; thus, they can be used for different routes of administration, such as parenteral, oral, dermal, ocular, pulmonary, and rectal. ${ }^{126-129}$

SLNs are made from solid lipids at room temperature and are stabilized by surfactant. SLNs can be obtained by a highpressure homogenization $(\mathrm{HPH})$ process that forms an average particle size of $<500 \mathrm{~nm}$ and a low microparticle content, other production procedures that use organic solvents (HPH/solvent evaporation), or the dilution of microemulsions. ${ }^{130-132}$ The schematic structure of SLNs is shown in Figure 1.

Holpuch et al tested a SLN formulation as a local oral cancer chemoprevention strategy. ${ }^{133}$ These authors demonstrated that SLNs composed of idarubicin hydrochloride $(0.2 \mathrm{mg}$ idarubicin $/ \mathrm{mL})$, sodium tetradecyl sulfate $(0.159 \mathrm{mg} / \mathrm{mL})$, emulsifying wax (2 mg/mL), polyoxyl 20 stearyl ether ([Brij ${ }^{\circledR} 78$; Uniqema, Wilmington, DE, USA] $2.3 \mathrm{mg} / \mathrm{mL}$ ), and D-alpha-tocopheryl PEG 1,000 succinate ([vitamin-E TPGS] $3 \mathrm{mg} / \mathrm{mL}$ ) and SLNs composed of BODIPY ${ }^{\circledR}$ FL C12 (Molecular Probes, Inc., Eugene, OR, USA) $(50 \mu \mathrm{g} / \mathrm{mL})$, emulsifying wax ( $2 \mathrm{mg} / \mathrm{mL})$, and polyoxyl 20 stearyl ether ([Brij $\left.{ }^{\circledR} 78\right] 4.0 \mathrm{mg} / \mathrm{mL}$ ) underwent internalization by OSCC cells and could provide higher final intracellular levels relative to bolus administration. Furthermore, the penetration and subsequent internalization of nanoparticles within proliferating basal layer cells demonstrates the feasibility of nanoparticle formulations for local delivery and the stabilization of oral chemopreventive compounds. ${ }^{133}$

However, SLNs have some limitations because the HPH process leads to drug degradation, the coexistence of different lipid modifications and colloidal species, and a low drug-loading capacity, and because of the kinetics of the distribution processes. ${ }^{134}$

To overcome these difficulties, a new generation of SLNs has emerged, ie, NLCs, which consist of solid matrix entrapping variable liquid lipid nanocompartments, as shown in Figure 1. The presence of liquid lipid nanocompartments avoids solid lipid crystallization and improves the drug payload and release because these are still controlled by a surrounding solid lipid barrier. ${ }^{135-137}$ 


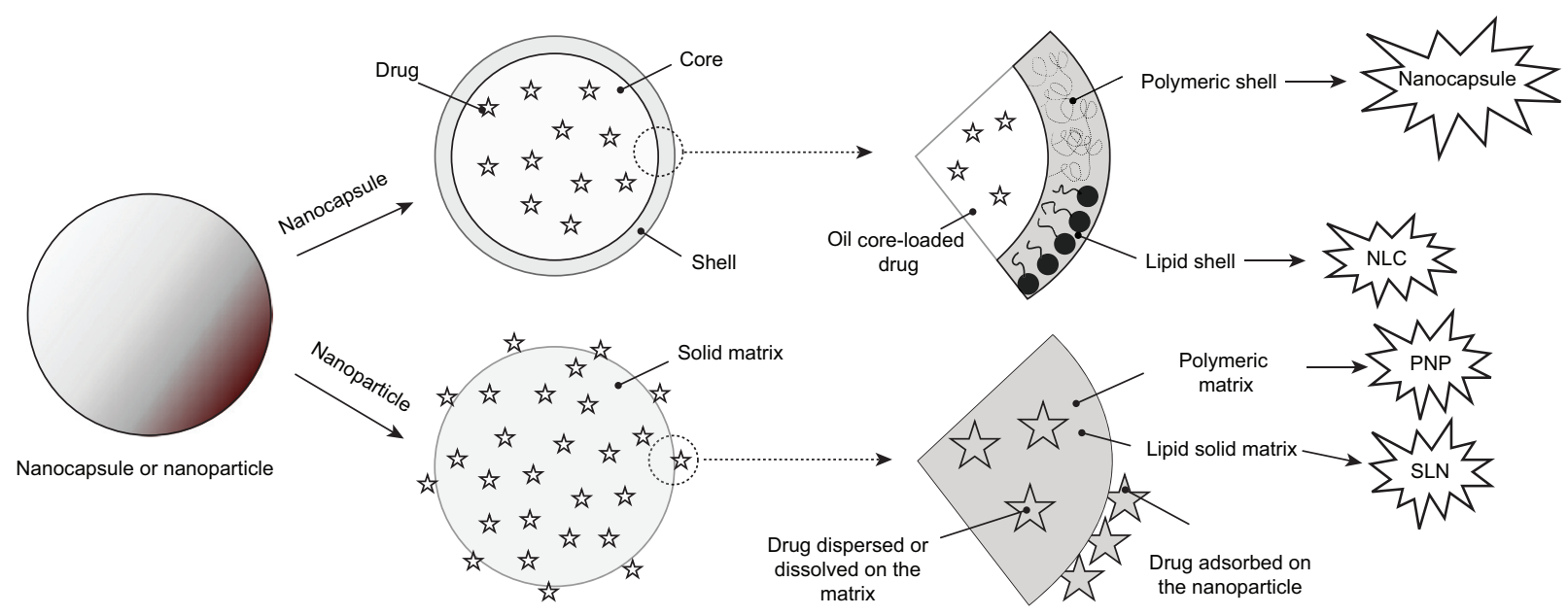

Figure I Schematic differences between nanocapsule, nanostructured lipid carrier (NLC), polymeric nanoparticle (PNP), and solid lipid nanoparticle (SLN) drug delivery systems.

Aditya et al made curcumin and genistein co-loaded NLCs based on oleic acid, lecithin, glycerol monostearate, and Tween ${ }^{\circledR} 80$ (Meryer (Shanghai) Chemical Technology Co., Ltd, Shanghai, People's Republic of China). ${ }^{138}$ These NLCs were found to be promising vehicles for the oral delivery of poorly bioaccessible molecules such as curcumin and genistein. In addition, NLCs had great effects against prostate cancer due to the enhanced intracellular uptake of NLCs by cells. ${ }^{138}$ Curcumin has also shown encouraging results in in vitro and in vivo models of OSCC. ${ }^{139}$ Therefore, future extensive research can determine the beneficial effects of curcumin-loaded NLCs for oral cancer treatment.

Chinsriwongkul et al researched NLCs based on a blend of cetyl palmitate and different liquid lipids, including soybean oil, medium-chain triglyceride, soybean oil/oleic acid (3:1) and medium-chain triglyceride/oleic acid (3:1), at a 1:1 weight ratio for the parenteral delivery of the anticancer drug all-trans retinoic acid (ATRA). ${ }^{140}$ NLCs based on oleic acid enhanced the ATRA loading capacity in the NLCs; however, all ATRA-loaded NLCs had prolonged release of ATRA in addition to being more cytotoxic than the free drug in an in vitro model of leukemia and hepatic cancer cells. ${ }^{140}$ ATRA-loaded NLCs could also be assessed in OSCC because retinoic acid is also effective at preventing the development of oral cancers. ${ }^{141,142}$

Liu et al designed DTX-loaded NLCs (DTX-NLCs) based on stearic acid, glyceryl monostearate, soya lecithin, and oleic acid prepared by the modified film ultrasonicationdispersion method. ${ }^{143}$ DTX was held in the lipid core of NLCs, which results in a prolonged release that could reduce the frequency of administration. Furthermore, DTX-NLCs had more cytotoxicity than free DTX, which is likely because
DTX-NLCs carry drugs into cancer cells by endocytosis and enhance intracellular drug accumulation by nanoparticle uptake. ${ }^{143}$ These results are promising for cancer therapy, including that for oral cancer, because DTX provides an alternative for the management of OSCC. ${ }^{144}$

Zhang et al aimed to develop three NLC formulations (NLC, PEG-NLC, distearoylphosphatidylethanolamine (DSPE)-PEG-NLC) for etoposide (VP16) and evaluate potential NLCs as an oral delivery system. ${ }^{145}$ The NLCs were based on VP16 (15 mg), monostearin (100 mg), soybean oil (30 mg), and soya lecithin (70 mg); PEG-NLCs were based on VP16 (15 mg), monostearin (100 mg), soybean oil (30 mg), soya lecithin (70 mg), and PEG-40 (140 mg); and DSPE-PEG-NLCs were based on VP16 (15 mg), monostearin (100 mg), soybean oil (30 mg), soya lecithin (70 mg), PEG-40 (140 mg), and DSPE-PEG (12 mg). All NLCs were prepared by an emulsification and low-temperature solidification method. A pharmacokinetic study conducted in rats revealed that the relative bioavailability of VP16NLCs, VP16-PEG-40-NLCs, and VP16-DSPE-NLCs was enhanced approximately 1.8-, 3.0-, and 3.5-fold, respectively, compared with a VP16 suspension. ${ }^{145}$ Moreover, VP16DSPE-NLCs showed the highest cytotoxicity against human epithelial-like lung carcinoma cells, which is likely due to NLC absorption at the cell surface and the release of VP16 close to the membrane, or NLC was internalized in cells and then released from the nanoparticles. ${ }^{145}$ These formulations may also provide an alternative for the treatment of oral cancer because VP16 also appears to have action in OSCC. ${ }^{146}$

Liu et al designed quercetin (QR)-loaded cationic NLCs that were based on a glycerol monostearate:medium-chain triglycerides ratio of $4: 1$, lecithin concentration of $3 \%$, 
didodecyldimethylammonium bromide concentration of $1 \%$, and QR concentration of 5\%. ${ }^{147}$ Liu et al reported that the QR-loaded cationic NLCs released QR slower than QR in solution released $\mathrm{QR}$ in vitro, mainly due to the slow erosion or degradation of the lipid matrix, which could prolong the residence time of the drug at the tumor site, eg, an oral cancer tumor site. ${ }^{147}$

Nanoparticles based on noble metals, particularly gold, have an immense potential for cancer diagnosis and therapy based on their surface-plasmon resonance-enhanced light scattering and absorption. ${ }^{148,149}$

El-Sayed et al prepared gold nanoparticles (AuNPs) by the citrate reduction of chloroauric acid. ${ }^{150}$ This group used a simple and inexpensive conventional microscope with proper rearrangement of the illumination system and a light collection system to image cells incubated with AuNPs or anti-epidermal growth factor receptor (EGFR) antibody-loaded AuNPs. Both types of AuNPs were then incubated with a single nonmalignant epithelial cell line, $\mathrm{HaCaT}$ (human keratinocytes), and two malignant epithelial cell lines, HOC 313 clone 8 and HSC 3 (human OSCC cell lines). The results showed that the scattering images and absorption spectra recorded from antiEGFR antibody-conjugated AuNPs incubated with cancerous and noncancerous cells were different and provided a potential technique for oral cancer diagnostics. ${ }^{150}$

Kah et al also investigated AuNPs for the early diagnosis of oral cancer based on surface plasmon resonance. ${ }^{151}$ These authors prepared AuNPs via the reduction of $0.259 \mathrm{mM}$ hydrogen tetrachloroaurate by $34 \mathrm{mM}$ trisodium citrate (Sigma-Aldrich Co., St Louis, MO, USA) at a temperature of $90^{\circ} \mathrm{C}$, and the AuNPs were conjugated to a monoclonal anti-EGFR antibody as a cancer biomarker for imaging via established protocols for the passive absorption of anti-EGFR on the surface of AuNPs. It was demonstrated that the use of EGFR-loaded AuNPs improved optical contrast under reflectance-mode imaging in vitro. Furthermore, the use of gold nanoparticles in surface-enhanced Raman scattering enhanced Raman spectroscopy signals for the analysis of cancer-related chemical changes in saliva. ${ }^{151}$

Afifi et al used hamster buccal pouch carcinoma as a model for OSCC to study the effects of plasmonic photothermal therapy using AuNPs combined with visible laser irradiation. ${ }^{152}$ AuNPs were synthesized using the citrate reduction method. The results demonstrated an amplified decrease in proliferation rates for cancer cells upon plasmonic photothermal therapy using AuNPs in addition to maintaining no adverse effects on normal cells, which can be explained by the enhanced permeability and retention effect. These findings indicate that AuNPs directly injected into hamster buccal pouch carcinomas can be used as a treatment for human OSCC in the future. ${ }^{152}$

\section{Liposomes}

Liposomes are unilamellar or multilamellar microscopic particles composed of membrane-like lipid layers, often phospholipids and cholesterol, surrounding aqueous compartments, ${ }^{124,153}$ as depicted in Figure 2.

Liposomes are the most widely used drug delivery systems for the systemic administration of many drugs for decreasing drug toxicity and increasing their accumulation at target sites. ${ }^{154}$ Therefore, liposomes have been intensively studied for the delivery of chemotherapeutic drugs to improve therapeutic efficacy and decrease the toxicity to normal cells. ${ }^{155}$

Furthermore, liposome-based formulations for gene therapy, such as synthetic cationic liposomal-DNA called

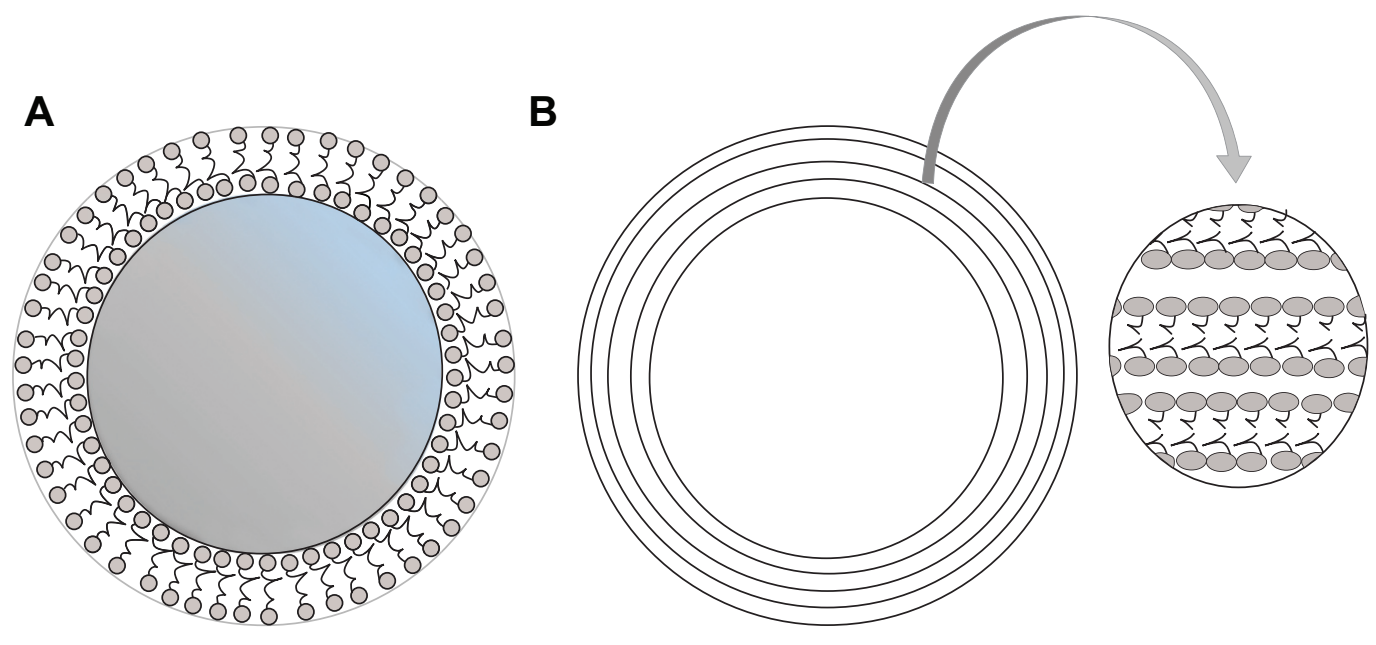

Figure 2 Schematic representation of unilamellar (A) and multilamellar (B) liposomes.

Note: The arrow indicates an enlarged view of the outer layers of multilamellar liposomes. 
lipoplexes, have clear potential, particularly for oral cancer treatment. ${ }^{156}$

In this context, Konopka et al investigated the effects of high concentrations of fetal bovine serum on the transfection efficiency of a polycationic liposome (Metafectene ${ }^{\mathrm{TM}}$; Biontex Laboratories $\mathrm{GmbH}$, München, Germany) and a polyamine reagent (GeneJammer; Agilent Technologies, Santa Clara, CA, USA) in HSC-3 and H357 human OSCC cells. The results showed that both polycationic liposomes could mediate gene delivery, which is not excessively inhibited even in the presence of $60 \%$ fetal bovine serum; therefore, they can be used in the delivery of genes in biological environments. ${ }^{157}$

Figueiró Longo et al studied the effects of photodynamic therapy mediated by a liposomal formulation prepared by dimyristoyl phosphatidylcholine in the presence and absence of additives such as cholesterol or cardiolipin to release aluminum phthalocyanine chloride, a photosensitizer, in tongue tumors induced in Swiss mice. ${ }^{158}$ This treatment produced intense necrosis in the tumor tissue accompanied by the infiltration of polymorphonuclear cells and thrombi formation on tumor-associated blood vessels. Thus, these results showed that photodynamic therapy mediated by a liposomal formulation of aluminum phthalocyanine chloride can be effective against chemically induced oral cancer. ${ }^{158}$

Velloso et al showed that liposomal aluminum phthalocyanine chloride-based photodynamic therapy inhibits the phosphatidylinositol 3-kinase/Akt/mammalian target of rapamycin (PI3K/Akt/mTOR) signaling pathway in cultured human OSCC cells. ${ }^{159}$ mTOR, a $289 \mathrm{kDa}$ serine/threonine kinase located downstream of the PI3K/Akt pathway, has been shown to be a major regulator of cell growth, proliferation, migration, differentiation, and survival. In OSCC, activation of PI3K is a frequent event, and mTOR can be involved in the pathophysiology of oral cancer. Thus, these results are promising for oral cancer treatment. ${ }^{159}$

\section{Hydrogels}

A hydrogel is a mesh of hydrophilic polymeric chains dispersed in water ${ }^{160}$ that is swellable and can release drugs for dissolution and disintegration through the spaces in their mesh, as shown in Figure 3. In addition to swelling, physical properties include permeability, mechanical resistance, and surface aspects that can be modulated through structural modification. ${ }^{161}$

Hydrogels are attractive for oral administration because their polymeric chains can closely interact with saliva glycoproteins, causing a mucoadhesion phenomenon. There has been a great deal of interest in the use of hydrogels as chemotherapeutic drug delivery systems for drugs including paclitaxel, doxorubicin, DTX, tamoxifen, and cisplatin. ${ }^{162-171}$ Furthermore, studies have revealed that strategies are required to overcome the disadvantages of chemotherapeutic drugs such as cisplatin, which is usually intravenously administered, whereby $90 \%$ becomes linked to hemoproteins and $10 \%$ is free to enter into the cells.

In this context, a research group investigated the incorporation of cisplatin loaded-hydrogels called P9, CP2, $\mathrm{MH}$ 2, and $\mathrm{CMH} 2 .{ }^{172} \mathrm{~A}$ stock solution of cisplatin was added stepwise to each polymer solution. The acrylic hydrogels P9 and CP2, which contain a carboxyl group, were obtained by free radical polymerization of the monomers N-acryloyl1-phenylalanine and $\mathrm{N}$-isopropylacrylamide (NIPAAm), and they were cross-linked with N,N'-ethylene-bis-acrylamide.

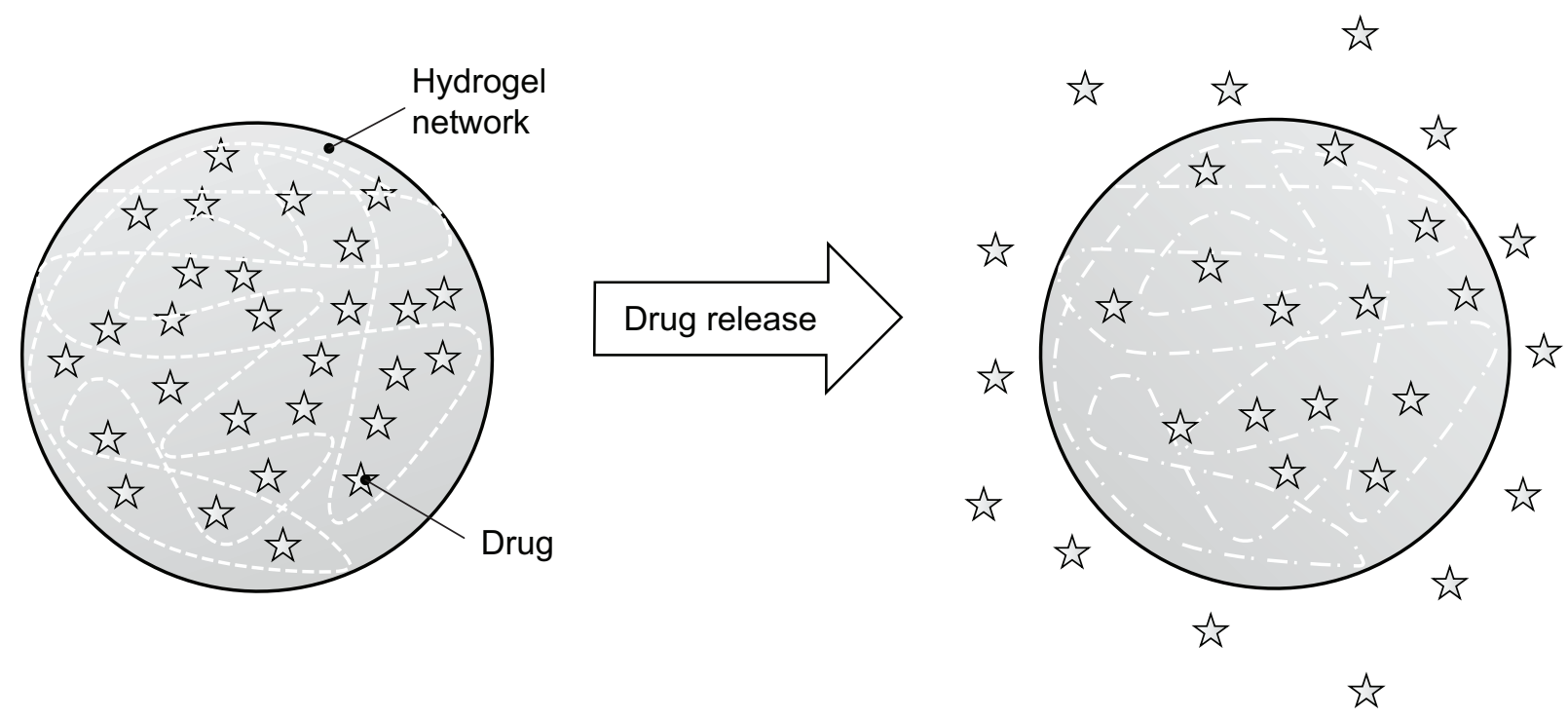

Figure 3 Hydrophilic polymeric chains network and release the drug for dissolution through the spaces of their mesh. 
MH2 and CMH2 hydrogels were obtained by free radical polymerization of the methacrylate monomer N-methacryloyl-1-histidine and NIPAAm, and the authors assessed the in vitro cytotoxicity of cisplatin-loaded hydrogels. They reported that $\mathrm{P} 9$ hydrogels could modulate the rate of cisplatin release. ${ }^{172} \mathrm{P} 9$ hydrogels have also been described as a promising platform for chemotherapeutic treatment, including that for oral cancers. ${ }^{173}$

Moura et al investigated in vitro cisplatin release from chitosan hydrogels cross-linked with glycerol phosphate disodium salt and chitosan hydrogels that were ionic/covalently co-cross-linked. ${ }^{174}$ Their results demonstrated that the rate of release of cisplatin from ionic cross-linked chitosan hydrogels was significantly lower than that for chitosan hydrogels ionic/ covalently co-cross-linked, and the amount of drug released was also quite different $(60 \%-70 \%$ for hydrogels containing genipin against $20 \%$ for ionic hydrogels). Despite these differences, the release profiles were similar for both types of hydrogels, with an initial burst reaching a maximum concentration at approximately 2 to 3 hours. The researchers concluded that hydrogels containing both cross-linking agents can improve the chemical and mechanical properties presented when compared with hydrogels obtained with only one of the reticulating agents, ${ }^{174}$ making it attractive for the treatment of oral cancers because the release profile of the system occurs quickly, thus releasing the drug formulation before it is removed from the oral cavity by the salivary flow. ${ }^{175}$

Emoto et al studied hydrogels obtained with crosslinkable hyaluronic acid for the intraperitoneal administration of cisplatin for extended retention and consequent action against peritoneal carcinomatosis. ${ }^{176}$ Hyaluronic acid was dissolved in water and sodium periodate was added and stirred for 2 hours. Afterward, ethylene glycol was added to stop the reaction, and the mixture was immediately dialyzed against water. The formation and swelling kinetics of hydrogels and the in vitro release kinetics of cisplatin from hydrogels were studied. The tests showed that there was sustained cisplatin release within 4 days. The researchers also evaluated the antitumor effects of the intraperitoneal administration of cisplatin-loaded acid hyaluronic hydrogels using a mouse model of gastric cancer. They observed a significant reduction in the weight of the peritoneal nodules in the gel-cisplatin group, whereas no significant reduction was detected in a phosphate-buffered saline-cisplatin group. It was concluded that this hydrogel is desirable for retention and modulates the release of cisplatin, thus increasing its antitumor effects. ${ }^{176}$

Researchers have tested a system composed of a heatsensitive copolymer formed by PEG-poly( $\varepsilon$-caprolactone)-
PEG (PECE) for the incorporation of suberoylanilide hydroxamic acid (SAHA) with cisplatin and subsequently evaluated the in vitro release profile of these drugs against oral carcinoma. ${ }^{152}$ For the formation of hydrogels, the PECE copolymer was first completely dissolved in water and cooled to $4^{\circ} \mathrm{C}$ to form a colloidal solution. SAHA and cisplatin solutions were then mixed into the PECE colloidal solution to form a homogeneous solution, and the PECE concentration was maintained at 30\% (w/w). The authors concluded that the SAHA-cisplatin/PECE hydrogel system with direct intratumoral injections may be a useful method for the treatment of oral cancer and other solid tumors. ${ }^{177}$

\section{Liquid crystals}

LCs are materials in a differential state, demonstrating a property between a solid and a liquid. This state is called mesophase: the prefix "meso-" means "intermediate". ${ }^{178}$

LCs are divided into two categories: thermotropics, which are structured by means of temperature, and lyotropics, which occur by association with amphipathic compounds and solvents. The mesophase lyotropics are mostly lamellar, hexagonal, or cubic, ${ }^{179}$ as shown in Figure 4.

LCs are usually based on water as a solvent, surfactant (may contain cosurfactants), and an oily phase. One of the advantages of LCs is that they can be stored for long periods because they are thermodynamically stable. ${ }^{180}$

Polarized light microscopy is one of the characterization techniques that is used for the preliminary identification of mesophase LCs. ${ }^{181}$ In this analysis, a sample undergoes the incidence of polarized light, which is enough to deflect light and is called anisotropic (it can be mesophase lamellar or hexagonal). However, if the latter does not bend light, it is isotropic (cubic arrangements); therefore, other techniques are needed for confirming this structure, ${ }^{179}$ including small-angle X-ray scattering, small-angle neutron scattering, neutron diffraction, nuclear magnetic resonance, and cryofracture electron microscopy. ${ }^{179,182,183}$

The LC systems significantly change the drug release profile and reduce the toxicity of drugs, improving clinical efficiency. ${ }^{178}$ Hosmer et al in 2012, studied mesophase lamellar LCs formed with glycerides for the incorporation of the anticancer drug paclitaxel. ${ }^{184}$ Paclitaxel is highly effective against various types of cancer, including oral cancer, ${ }^{185-187}$ however, it has severe adverse effects associated with systemic drug administration, including hypersensitivity reactions, thrombocytopenia, and neutropenia. ${ }^{188,189}$ Hosmer et $\mathrm{al}^{184}$ found that, among the formulations studied, the Brij-based lamellar phase containing 20\% medium-chain 
A

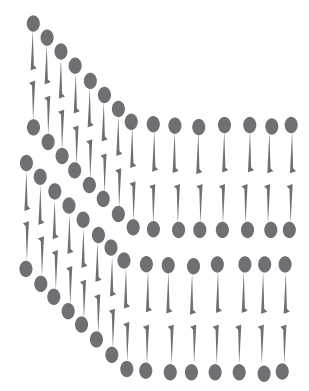

B

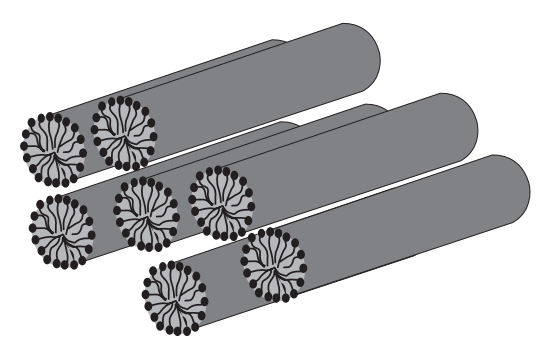

C

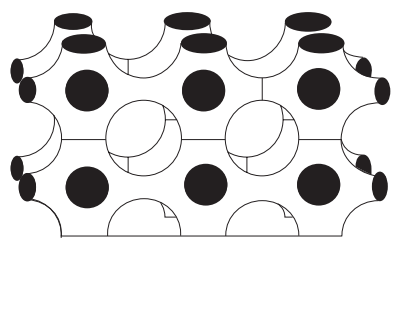

Figure 4 Schematic representation of lamellar (A), hexagonal (B), and cubic (C) liquid crystal mesophases.

mono-/diglycerides maximized the delivery of paclitaxel and showed good efficacy against paclitaxel-sensitive fibroblasts; therefore, LCs may be a promising strategy for the treatment of cancers, including oral cancer.

Zeng et al developed liquid crystalline nanoparticles consisting of soy phosphatidyl choline and glycerol dioleate for the incorporation of paclitaxel using a solvent precursor method described by Rizwan et al in which a 50:50 (w/w) mixture of soy phosphatidyl choline and glycerol dioleate was agitated for 3 hours to form a uniform oily phase. ${ }^{190,191} 4$-(2hydroxyethyl)-1-piperazineethanesulfonic acid (HEPES) was then carefully added followed by stirring at room temperature for 24 hours. The precursor of LC was added under magnetic stirring at $60^{\circ} \mathrm{C}$, forming a coarse dispersion. This dispersion was subsequently homogenized using a Microfluidizer ${ }^{\circledR}$ (Microfluidics, Newton, MA, USA) at a pressure of 10,000 psi for three cycles and 30,000 psi for two cycles. ${ }^{191}$ The systems were characterized by polarized light microscopy, indicating the coexistence of reversed cubic and hexagonal phases in the optimized LC matrix. Transmission electron microscopy and cryo-field emission scanning electron microscopy revealed the internal water channel and "twig-like" surface morphology of the LC matrix. Tests were performed, including pharmacokinetics in vivo, and particle size distribution, phase behavior characterization, transmission electron microscopy, and cryo-field emission scanning electron microscopy in vitro. Zeng et al concluded that these systems demonstrated potential as nanocarriers for waterinsoluble drugs such as paclitaxel, improving intravenous bioavailability. ${ }^{191}$

\section{Complexes of cyclodextrins}

Cyclodextrins are cyclical and composed of at least six units of glucose, ${ }^{192}$ resulting in a truncated cone form with a hollow cavity, ${ }^{193}$ as shown in Figure 5.

Although natural cyclodextrins (the best known cyclodextrins include $\alpha-, \beta$-, and $\gamma$-cyclodextrin) are of interest for the development of pharmaceutical formulations by presenting excellent biocompatibility, ${ }^{194}$ the ability to mask undesirable organoleptic properties of drugs, and the ability to increase solubility and permeability, ${ }^{195}$ these compounds demonstrate limitations for the transport of drugs, enabling the loading of only lipophilic drugs by virtue of the cyclodextrin hydrophilic exterior and interior hydrophobic cavity. ${ }^{196}$ Soon, natural cyclodextrins may be produced with chemical modifications in accordance with the interest in this field, ${ }^{197}$ enabling the attainment of cyclodextrins with both lipophilic and conjugated polar groups, making them amphiphilic. ${ }^{198}$

Cyclodextrins represent a group of excipients with great potential for use in pharmaceutical formulations. Once the bioavailability and multifunctional features of cyclodextrins are able to reduce the undesirable properties of drugs that are included in complexes, application via several routes of administration will be enabled. It is also important to highlight the ability to include drugs with solid or liquid characteristics. ${ }^{199}$

Ramineni et al studied cyclodextrins for the inclusion of imiquimod to treat precancerous dysplastic lesions of the oral cavity. ${ }^{200}$ This group developed a mucoadhesive film for the conveyance of a highly hydrophobic drug. To prepare these films, a polymer aqueous solution of polyvinylpyrrolidone mixed with ethanol following the addition of propylene

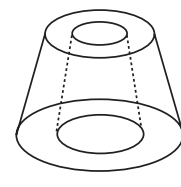

Cyclodextrin
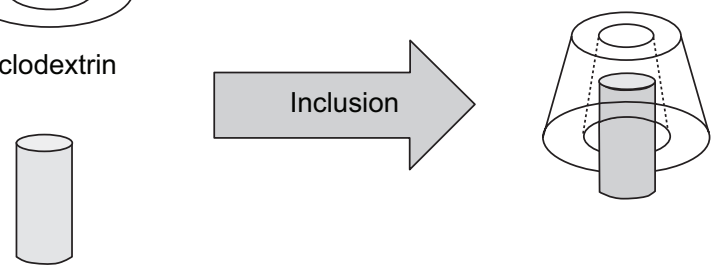

Drug

Figure 5 Representation of cyclodextrin, drug, and cyclodextrin complex. 
glycol as a plasticizer was used. At the same time, a solution of carboxymethylcellulose was prepared and added to polymer aqueous solution at high speed. The polymer mixture was dried, forming films, and the antineoplastic agent was incorporated by four different methods: sonication, solubilization in linoleic acid, complex formation by co-evaporation, and solubilization in methanol and acetate buffer. The films were translucent and flexible, with the exception of those prepared with linoleic acid; therefore, the films are a promising platform for the delivery of drugs with mucoadhesion properties, which are able to be administered at the desired location in addition to sustaining the delivery of imiquimod. ${ }^{200}$

Researchers have also developed a new type of hollow complex based on the combination of cyclodextrin with hyaluronic acid, which can be added to paclitaxel. ${ }^{201}$ The system was innovatively performed and was associated with the pursuit of controlled drug release by complexation with cyclodextrins that are recognized by cancer cells and sensitized to enzymatic hydrolysis caused by the natural biological properties of hyaluronic acid. Under physiological conditions, paclitaxel was released slowly, demonstrating that the cyclodextrins were stable. ${ }^{201}$

A group of researchers ${ }^{202}$ developed $\alpha$-cyclodextrins with $\mathrm{pH}$-sensitive nanoparticles. To reach the specific location of a tumor that is around $\mathrm{pH}$ 5.7-7.8, this group prepared a system for drug targeting. These authors incorporated paclitaxel and analyzed the activity of various tumor cells in addition to conducting tests in vivo in mice with melanoma. These mice were given a single intravenous dose of paclitaxel $(10 \mathrm{mg} / \mathrm{kg})$ and were compared with a negative control that was administered saline solution, and a reduction in tumor cells was observed. Thus, it is noted that formulated nanomedicines can effectively reverse the multidrug resistance of cancer cells resistant to paclitaxel. In summary, $\mathrm{pH}$-sensitive $\alpha$-cyclodextrin materials can be conveniently produced by a facile acetonation process, which may be further processed into NPs with controllable size and size distribution. The results demonstrated that the systems have biocompatibility and lead to a reduction in adverse effects and improved antitumor activity. ${ }^{202}$

\section{New approaches and challenges}

The ultimate goal of cancer treatment is to kill as many cancer cells as possible without affecting healthy cells. However, the ability of a drug to target specific sites in the body to achieve defined therapeutic effects needs improvement. In this context, nanodelivery systems emerge as a potential alternative for overcoming some previously encountered obstacles to efficiently target several cancer cell types because they have shown several promising characteristics, including optimal anti-oral tumor effects, which are not available with traditional chemotherapy.

Thus, the US Food and Drug Administration (FDA) recently approved a clinical trial of a nanoparticle-based system to use in humans for treatment of solid tumors. ${ }^{203}$ Furthermore, Yang et al in 2003, evaluated targeted delivery to cervical lymph nodes by perioral cancer submucosal injection of cucurbitacin BE polylactic acid nanoparticles (CuBE-PLA-NPs) and their clinical therapy efficacy. The results showed that the drug concentrations in cervical lymph nodes after CuBE-PLA-NP injection were far higher than those in the control group. Furthermore, the drug concentrations in the blood in the CuBE-PLA-NP group were far lower than those in the control group. ${ }^{204}$

Hence, in the near future, oncologists and patients will benefit from suitable nanotechnology-based drug delivery systems that could lead to improved therapeutic outcomes with reduced costs. There are few clinical studies on oral cancer in the field of nanotechnology, but nanotechnology is also predicted to alter health care in dentistry, with novel methods of identifying the cancer as well as customization of a patient's therapeutic profile. ${ }^{205}$

Further studies are needed to turn concepts of nanotechnology into practical applications and to elucidate correct drug doses and ideal release from these systems for the treatment of several cancers with different molecular and cellular mechanisms.

\section{Acknowledgments}

The authors are grateful to FAPESP (São Paulo, Brazil), CNPq (Brasília, Brazil), and PADC/FCF-UNESP (Araraquara, Brazil) for research fellowships.

\section{Disclosure}

The authors report no conflicts of interest in this work.

\section{References}

1. Jemal A, Bray F, Center MM, Ferlay J, Ward E, Forman D. Global cancer statistics. CA Cancer J Clin. 2011;61(2):69-90.

2. Siegel R, Naishadham D, Jemal A. Cancer statistics, 2013. CA Cancer J Clin. 2013;63(1):11-30.

3. Epstein JB, Zhang L, Rosin M. Advances in the diagnosis of oral premalignant and malignant lesions. J Can Dent Assoc. 2002;68(10): 617-621.

4. Llewellyn CD, Johnson NW, Warnakulasuriya KA. Risk factors for oral cancer in newly diagnosed patients aged 45 years and younger: a case-control study in Southern England. J Oral Pathol Med. 2004; 33(9):525-532.

5. Chitapanarux I, Lorvidhaya V, Sittitrai P, et al. Oral cavity cancers at a young age: analysis of patient, tumor and treatment characteristics in Chiang Mai University Hospital. Oral Oncol. 2006;42(1):83-88. 
6. Binnie WH, Rankin KV, Mackenzie IC. Etiology of oral squamous cell carcinoma. J Oral Pathol. 1983;12(1):11-29.

7. Douglass CW, Gammon MD. Reassessing the epidemiology of lip cancer. Oral Surg Oral Med Oral Pathol. 1984;57(6):631-642.

8. de Rosa I, Staibano S, Lo Muzio L, et al. Potentially malignant and malignant lesions of the lip. Role of silver staining nucleolar organizer regions, proliferating cell nuclear antigen, p53, and c-myc in differentiation and prognosis. J Oral Pathol Med. 1999;28(6):252-258.

9. Frierson HF Jr, Cooper PH. Prognostic factors in squamous cell carcinoma of the lower lip. Hum Pathol. 1986;17(4):346-354.

10. Näsman A, Attner $P$, Hammarstedt $L$, et al. Incidence of human papillomavirus (HPV) positive tonsillar carcinoma in Stockholm, Sweden: an epidemic of viral-induced carcinoma? Int J Cancer. 2009;125(2): 362-366.

11. Hafkamp HC, Speel EJ, Haesevoets A, et al. A subset of head and neck squamous cell carcinomas exhibits integration of HPV 16/18 DNA and overexpression of p16INK4A and p53 in the absence of mutations in p53 exons 5-8. Int $J$ Cancer. 2003;107(3):394-400.

12. Ragin CC, Taioli E. Survival of squamous cell carcinoma of the head and neck in relation to human papillomavirus infection: review and meta-analysis. Int J Cancer. 2007;121(8):1813-1820.

13. Huang B, Chen H, Fan M. A postulated role for human papillomavirus (HPV) in the transformation and proliferation of oral squamous cell carcinoma (OSCC). Med Hypotheses. 2008;70(5):1041-1043.

14. Petersen PE. Oral cancer prevention and control - the approach of the World Health Organization. Oral Oncol. 2009;45(4-5):454-460.

15. Jones DL, Rankin KV. Oral cancer and associated risk factors. In: Cappelli DP, Mobley CC, editors. Prevention in Clinical Oral Health Care. St Louis, MO: Mosby Elsevier; 2008:68-77.

16. Su CC, Yang HF, Huang SJ, Lian IeB. Distinctive features of oral cancer in Changhua County: high incidence, buccal mucosa preponderance, and a close relation to betel quid chewing habit. J Formos Med Assoc. 2007;106(3):225-233.

17. Chen CJ, You SL, Lin LH, Hsu WL, Yang YW. Cancer epidemiology and control in Taiwan: a brief review. Jpn J Cancer Res. 2002;32 Suppl: S66-S81.

18. Kantola S, Parikka M, Jokinen K, et al. Prognostic factors in tongue cancer - relative importance of demographic, clinical and histopathological factors. Br J Cancer. 2000;83(5):614-619.

19. Sankaranarayanan R, Masuyer E, Swaminathan R, Ferlay J, Whelan S. Head and neck cancer: a global perspective on epidemiology and prognosis. Anticancer Res. 1998;18(6B):4779-4786.

20. Carvalho AL, Magrin J, Kowalski LP. Sites of recurrence in oral and oropharyngeal cancers according to the treatment approach. Oral Dis. 2003;9(3):112-118.

21. Shah JP, Lydiatt W. Treatment of cancer of the head and neck. $C A$ Cancer J Clin. 1995;45(6):352-368.

22. Onofre MA, Sposto MR, Navarro CM, Motta ME, Turatti E, Almeida RT Potentially malignant epithelial oral lesions: discrepancies between clinical and histological diagnosis. Oral Dis. 1997;3(3):148-152.

23. Bhalang K, Suesuwan A, Dhanuthai K, Sannikorn P, Luangjarmekorn L, Swasdison S. The application of acetic acid in the detection of oral squamous cell carcinoma. Oral Surg Oral Med Oral Pathol Oral Radiol Endod. 2008;106(3):371-376.

24. Epstein JB, Silverman S Jr, Epstein JD, Lonky SA, Bride MA. Analysis of oral lesion biopsies identified and evaluated by visual examination, chemiluminescence and toluidine blue. Oral Oncol. 2008;44(6): 538-544.

25. Wilder-Smith P, Lee K, Guo S, et al. In vivo diagnosis of oral dysplasia and malignancy using optical coherence tomography: preliminary studies in 50 patients. Lasers Surg Med. 2009;41(5):353-357.

26. Koch FP, Kaemmerer PW, Biesterfeld S, Kunkel M, Wagner W. Effectiveness of autofluorescence to identify suspicious oral lesions - a prospective, blinded clinical trial. Clin Oral Investig. 2010;15(6): 975-982.

27. Koch FP, Kunkel M, Biesterfeld S, Wagner W. Diagnostic efficiency of differentiating small cancerous and precancerous lesions using mucosal brush smears of the oral cavity - a prospective and blinded study. Clin Oral Investig. 2010;15(5):763-769.
28. Scully C, editor. Cancer. In: Oral and Maxillofacial Medicine: The Basis of Diagnosis and Treatment. 3rd ed. New York, NY: Churchill Livingstone Elsevier; 2013:204-217.

29. Csikar J, Aravani A, Godson J, Day M, Wilkinson J. Incidence of oral cancer among South Asians and those of other ethnic groups by sex in West Yorkshire and England, 2001-2006. Br J Oral Maxillofac Surg. 2013;51(1):25-29.

30. Weinberg MA, Estefan DJ. Assessing oral malignancies. Am Fam Physician. 2002;65(7):1379-1384.

31. Homer JJ, Greenman J, Stafford ND. Angiogenic cytokines in serum and plasma of patients with head and neck squamous cell carcimona. Clin Otolaryngol Allied Sci. 2000;25(6):570-576.

32. Weinberg RA. Tumor suppressor genes. Science. 1991;254(5035): 1138-1146.

33. Mehrotra R, Vasstrand EN, Ibrahim SO. Recent advances in understanding carcinogenicity of oral squamous cell carcinoma: from basic molecular biology to latest genomic and proteomic findings. Cancer Genomics Proteomics. 2004;1(4):283-294.

34. Khan Z, Bisen PS. Oncoapoptotic signaling and deregulated target genes in cancers: special reference to oral cancer. Biochim Biophys Acta. 2013;1836(1):123-145.

35. Vogelstein B, Kinzler KW. The multistep nature of cancer. Trends Genet. 1993;9(4):138-141.

36. Mehrotra R, Yadav S. Oral squamous cell carcinoma: etiology, pathogenesis and prognostic value of genomic alterations. Indian J Cancer. 2006;43(2):60-66.

37. Hollstein M, Sidransky D, Vogelstein B, Harris CC. p53 mutations in human cancers. Science. 1991;253(5015):49-53.

38. Brennan JA, Boyle JO, Koch WM, et al. Association between cigarette smoking and mutation of the p53 gene in squamous-cell carcinoma of the head and neck. N Engl J Med. 1995;332(11):712-717.

39. Schantz SP. Basic science advances in head and neck oncology: the past decade. Semin Surg Oncol. 1995;11(3):272-279.

40. Califano J, Ahrendt SA, Meininger G, Westra WH, Koch WM, Sidransky D. Detection of telomerase activity in oral rinses from head and neck squamous cell carcinoma patients. Cancer Res. 1996;56(24): 5720-5722.

41. Miyoshi $\mathrm{Y}$, Tsukinoki K, Imaizumi T, et al. Telomerase activity in oral cancer. Oral Oncol. 1999;35(3):283-289.

42. Brachman DG, BeckettM, Graves D, HarafD, VokesE, Weichselbaum RR. p53 mutation does not correlate with radiosensitivity in 24 head and neck cancer cell lines. Cancer Res. 1993;53(16):3667-3669.

43. Harano N, Ono K, Hidaka K, Kai A, Nakanishi O, Inenaga K. Differences between orofacial inflammation and cancer pain. $J$ Dent Res. 2010;89(6):615-620.

44. Peters CM, Lindsay TH, Pomonis JD, et al. Endothelin and the tumorigenic component of bone cancer pain. Neuroscience. 2004;126(4): 1043-1052.

45. Pickering V, Jordan RC, Schmidt BL. Elevated salivary endothelin levels in oral cancer patients - a pilot study. Oral Oncol. 2007;43(1): $37-41$.

46. Schmidt BL, Pickering V, Liu S, et al. Peripheral endothelin A receptor antagonism attenuates carcinoma-induced pain. Eur J Pain. 2007;11(4): 406-414.

47. Pickering V, Jay Gupta R, Quang P, Jordan RC, Schmidt BL. Effect of peripheral endothelin-1 concentration on carcinoma-induced pain in mice. Eur J Pain. 2008;12(3):293-300.

48. Nyberg P, Ylipalosaari M, Sorsa T, Salo T. Trypsins and their role in carcinoma growth. Exp Cel Res. 2006;312(8):1219-1228.

49. Lam DK, Schmidt BL. Serine proteases and protease-activated receptor 2-dependent allodynia: a novel cancer pain pathway. Pain. 2010;149(2):263-272.

50. Russo A, Soh UJ, Trejo J. Proteases display biased agonism at protease-activated receptors: location matters! Mol Interv. 2009;9(2): $87-96$.

51. Amadesi S, Cottrell GS, Divino L, et al. Protease-activated receptor 2 sensitizes TRPV1 by protein kinase Cepsilon- and A-dependent mechanisms in rats and mice. $J$ Physiol. 2006;575(Pt 2):555-571. 
52. Zheng J, Tian X, Sun Y, Lu D, Yang W. pH-sensitive poly (glutamic acid) grafted mesoporous silica nanoparticles for drug delivery. Int J Pharm. 2013;450(1):296-303.

53. Davis BM, Lewin GR, Mendell LM, Jones ME, Albers KM. Altered expression of nerve growth factor in the skin of transgenic mice leads to changes in response to mechanical stimuli. Neuroscience. 1993;56(4): 789-792.

54. Klein R, Jing SQ, Nanduri V, O'Rourke E, Barbacid M. The trk protooncogene encodes a receptor for nerve growth factor. Cell. 1991;65(1): 189-197.

55. Glinsky GV, Ivanova AB, Vinnitsky VB, Arumäe U, Siigur J, Neuman T. Nerve growth factor may be the metastasis growth factor. Ann N Y Acad Sci. 1987;496:656-659.

56. Kolokythas A, Cox DP, Dekker N, Schmidt BL. Nerve growth factor and tyrosine kinase A receptor in oral squamous cell carcinoma: is there an association with perineural invasion? J Oral Maxillofac Surg. 2010;68(6):1290-1295.

57. Ye Y, Dang D, Zhang J, et al. Nerve growth factor links oral cancer progression, pain, and cachexia. Mol Cancer Ther. 2011;10(9): $1667-1676$

58. Okada Y, Ueno H, Katagiri M, et al. Experimental study of antiangiogenic gene therapy targeting VEGF in oral cancer. Odontology. 2010;98(1):52-59.

59. Riedel F, Götte K, Schwalb J, Wirtz H, Bergler W, Hörmann K. Serum levels of vascular endothelial growth factor in patients with head and neck cancer. Eur Arch Otorhinolaryngol. 2000;257(6):332-336.

60. Shang ZJ, Li JR, Li ZB. Circulating levels of vascular endothelial growth factor in patients with oral squamous cell carcinoma. Int J Oral Maxillofac Surg. 2002;31(5):495-498.

61. Mărgăritescu C, Pirici D, Simionescu C, et al. VEGF and VEGFRs expression in oral squamous cell carcinoma. Rom J Morphol Embryol. 2009;50(4):527-548.

62. Salimi M, Esfahani M, Habibzadeh N, et al. Change in nicotine-induced VEGF, PGE2 AND COX-2 expression following COX inhibition in human oral squamous cancer. J Environ Pathol Toxicol Oncol. 2012;31(4):349-356.

63. Colotta F, Allavena P, Sica A, Garlanda C, Mantovani A. Cancer-related inflammation, the seventh hallmark of cancer: links to genetic instability. Carcinogenesis. 2009;30(7):1073-1081.

64. Del Prete A, Allavena P, Santoro G, Fumarulo R, Corsi MM, Mantovani A. Molecular pathways in cancer-related inflammation. Biochem Med (Zagreb). 2011;21(3):264-275.

65. Kamp DW, Shacter E, Weitzman SA. Chronic inflammation and cancer: the role of the mitochondria. Oncology (Williston Park). 2011;25(5):400-410, 413.

66. Mignogna MD, Fedele S, Lo Russo L, Lo Muzio L, Bucci E. Immune activation and chronic inflammation as the cause of malignancy in oral lichen planus: is there any evidence? Oral Oncol. 2004;40(2): 120-130.

67. Li TJ, Cui J. COX-2, MMP-7 expression in oral lichen planus and oral squamous cell carcinoma. Asian Pac J Trop Biomed. 2013;6(8): 640-643.

68. Georgakopoulou EA, Achtari MD, Achtaris M, Foukas PG, Kotsinas A. Oral lichen planus as a preneoplastic inflammatory model. J Biomed Biotechnol. 2012;2012:759626.

69. Pontes HA, Pontes FS, Fonseca FP, et al. Nuclear factor kappa B and cyclooxygenase-2 immunoexpression in oral dysplasia and oral squamous cell carcinoma. Ann Diagn Pathol. 2013;17(1):45-50.

70. Mauro A, Lipari L, Leone A, et al. Expression of cyclooxygenase-1 and cyclooxygenase-2 in normal and pathological human oral mucosa. Folia Histochem Cytobiol. 2010;48(4):555-563.

71. Goulart Filho JA, Nonaka CF, da Costa Miguel MC, de Almeida Freitas R, Galvão HC. Immunoexpression of cyclooxygenase-2 and p53 in oral squamous cell carcinoma. Am J Otolaryngol. 2009;30(2):89-94.

72. Impola $\mathrm{U}$, Uitto $\mathrm{VJ}$, Hietanen $\mathrm{J}$, et al. Differential expression of matrilysin-1 (MMP-7), $92 \mathrm{kD}$ gelatinase (MMP-9), and metalloelastase (MMP-12) in oral verrucous and squamous cell cancer. J Pathol. 2004;202(1):14-22.
73. Vu TH, Werb Z. Matrix metalloproteinases: effectors of development and normal physiology. Genes Dev. 2000;14(17):2123-2133.

74. Werner JA, Rathcke IO, Mandic R. The role of matrix metalloproteinases in squamous cell carcinomas of the head and neck. Clin Exp Metastasis. 2002;19(4):275-282.

75. Egeblad M, Werb Z. New functions for the matrix metalloproteinases in cancer progression. Cancer. 2002;2(3):161-174.

76. Vairaktaris E, Serefoglou Z, Yapijakis C, et al. High gene expression of matrix metalloproteinase-7 is associated with early stages of oral cancer. Anticancer Res. 2007;27(4B):2493-2498.

77. Karin M. Nuclear factor-kappa B in cancer development and progression. Nature. 2006;441(7092):431-436

78. Bindhu OS, Ramadas K, Sebastian P, Pillai MR. High expression levels of nuclear factor kappa B and gelatinases in the tumorigenesis of oral squamous cell carcinoma. Head Neck. 2006;28(10):916-925.

79. Richmond A. Nf-kappa B, chemokine gene transcription and tumour growth. Nat Rev Immunol. 2002;2(9):664-674.

80. de Visscher JG. Behandeling en prognose van het mondholtecarcinoom [Treatment and prognosis of oral cancer]. Ned Tijdschr Tandheelkd. 2008;115(4):192-198. Dutch.

81. Adelstein DJ, Li Y, Adams GL, et al. An intergroup phase III comparison of standard radiation therapy and two schedules of concurrent chemoradiotherapy in patients with unresectable squamous cell head and neck cancer. J Clin Oncol. 2003;21(1):92-98.

82. Bachaud JM, Cohen-Jonathan E, Alzieu C, David JM, Serrano E, DalySchveitzer N. Combined postoperative radiotherapy and weekly cisplatin infusion for locally advanced head and neck carcinoma: final report of a randomized trial. Int J Radiat Oncol Biol Phys. 1996;36(5):999-1004.

83. Baselga J, Trigo JM, Bourhis J, et al. Phase II multicenter study of the antiepidermal growth factor receptor monoclonal antibody cetuximab in combination with platinum-based chemotherapy in patients with platinum-refractory metastatic and/or recurrent squamous cell carcinoma of the head and neck. J Clin Oncol. 2005;23(24):5568-5577.

84. Bonner JA, Harari PM, Giralt J, et al. Radiotherapy plus cetuximab for squamous-cell carcinoma of the head and neck. $N$ Engl J Med. 2006;354(6):567-578.

85. Catimel G, Verweij J, Mattijssen V, et al. Docetaxel (Taxotere): an active drug for the treatment of patients with advanced squamous cell carcinoma of the head and neck. EORTC Early Clinical Trials Group. Ann Oncol. 1994;5(6):533-537.

86. Clavel M, Vermorken JB, Cognetti F, et al. Randomized comparison of cisplatin, methotrexate, bleomycin and vincristine (CABO) versus cisplatin and 5-fluorouracil (CF) versus cisplatin (C) in recurrent or metastatic squamous cell carcinoma of the head and neck. A phase III study of the EORTC Head and Neck Cancer Cooperative Group. Ann Oncol. 1994;5(6):521-526.

87. Haddad R, Sonis S, Posner M, et al. Randomized phase 2 study of concomitant chemoradiotherapy using weekly carboplatin/paclitaxel with or without daily subcutaneous amifostine in patients with locally advanced head and neck cancer. Cancer. 2009;115(19): 4514-4523

88. Vermorken JB, Mesia R, Rivera F, et al. Platinum-based chemotherapy plus cetuximab in head and neck cancer. N Engl J Med. 2008;359(11): 1116-1127.

89. Vermorken JB, Remenar E, van Herpen C, et al. Cisplatin, fluorouracil, and docetaxel in unresectable head and neck cancer. $N$ Engl J Med. 2007;357(17):1695-1704

90. Vermorken JB, Trigo J, Hitt R, et al. Open-label, uncontrolled, multicenter phase II study to evaluate the efficacy and toxicity of cetuximab as a single agent in patients with recurrent and/or metastatic squamous cell carcinoma of the head and neck who failed to respond to platinumbased therapy. J Clin Oncol. 2007;25(16):2171-2177.

91. Terwogt JM, Schellens JH, Huinink WW, Beijnen JH. Clinical pharmacology of anticancer agents in relation to formulations and administration routes. Cancer Treat Rev. 1999;25(2):83-101.

92. Agüeros M, Ruiz-Gatón L, Vauthier C, et al. Combined hydroxypropylbeta-cyclodextrin and poly(anhydride) nanoparticles improve the oral permeability of paclitaxel. Eur J Pharm Sci. 2009;38(4):405-413. 
93. Devalapally H, Chakilam A, Amiji MM. Role of nanotechnology in pharmaceutical product development. J Pharm Sci. 2007;96(10): 2547-2565.

94. Kruijtzer CM, Beijnen JH, Schellens JH. Improvement of oral drug treatment by temporary inhibition of drug transporters and/or cytochrome P450 in the gastrointestinal tract and liver: an overview. Oncologist. 2002;7(6):516-530.

95. Kumar GP, Rajeshwarrao P. Nonionic surfactant vesicular systems for effective drug delivery - an overview. Acta Pharm Sin B. 2011;1(4): 208-219.

96. Manmode AS, Sakarkar DM, Mahajan NM. Nanoparticles-tremendous therapeutic potential: a review. International Journal of Pharm Tech Research. 2009;1(4):1020-1027.

97. Neha B, Ganesh B, Preeti K. Drug delivery to the brain using polymeric nanoparticles: a review. International Journal of Pharmaceutical and Life Sciences. 2013;2(3): 107-132.

98. Cho K, Wang X, Nie S, Chen ZG, Shin DM. Therapeutic nanoparticles for drug delivery in cancer. Clin Cancer Res. 2008;14(5): 1310-1316.

99. Couvreur P. Nanoparticles in drug delivery: past, present and future. Adv Drug Deliv Rev. 2013;65(1):21-23.

100. Kamimura M, Furukawa T, Akiyama S-I, Nagasaki Y. Enhanced intracellular drug delivery of $\mathrm{pH}$-sensitive doxorubicin/poly(ethylene glycol)-block-poly(4-vinylbenzylphosphonate) nanoparticles in multidrug resistant human epidermoid KB carcinoma cells. Biomater Sci. 2013;1(4):361-367.

101. Du F, Meng H, Xu K, et al. CPT loaded nanoparticles based on betacyclodextrin-grafted poly(ethylene glycol)/poly(L-glutamic acid) diblock copolymer and their inclusion complexes with CPT. Colloids Surf B Biointerfaces. 2014;113:230-236.

102. Ravikumara NR, Tiyaboonchai W, Madhusudhan B. Fabrication and characterization of genistein encapsulated poly (D, L) lactic acid nanoparticles for pharmaceutical application. Curr Nanosci. 2013; 9(2):293-302.

103. Panyam J, Zhou WZ, Prabha S, Sahoo SK, Labhasetwar V. Rapid endo-lysosomal escape of poly(DL-lactide-co-glycolide) nanoparticles: implications for drug and gene delivery. FASEB J. 2002;16(10): 1217-1226.

104. Ren F, Chen R, Wang Y, Sun Y, Jiang Y, Li G. Paclitaxel-loaded poly(n-butylcyanoacrylate) nanoparticle delivery system to overcome multidrug resistance in ovarian cancer. Pharm Res. 2011;28(4): 897-906.

105. Koo H, Min KH, Lee SC, et al. Enhanced drug-loading and therapeutic efficacy of hydrotropic oligomer-conjugated glycol chitosan nanoparticles for tumor-targeted paclitaxel delivery. J Control Release. 2013;172(3):823-831.

106. Lee KY, Mooney DJ. Alginate: properties and biomedical applications. Prog Polym Sci. 2012;37(1):106-126.

107. Das RK, Kasoju N, Bora U. Encapsulation of curcumin in alginatechitosan-pluronic composite nanoparticles for delivery to cancer cells. Nanomedicine. 2010;6(1):153-160.

108. Wang H, Zhao P, Liang X, et al. Folate-PEG coated cationic modified chitosan - cholesterol liposomes for tumor-targeted drug delivery. Biomaterials. 2010;31(14):4129-4138.

109. Mohanraj VJ, Chen Y. Nanoparticles - a review. Tropical Journal of Pharmaceutical Research. 2006;5(1):561-573.

110. Fan W, Yan W, Xu Z, Ni H. Formation mechanism of monodisperse, low molecular weight chitosan nanoparticles by ionic gelation technique. Colloids Surf B Biointerfaces. 2012;90:21-27.

111. Makadia HK, Siegel SJ. Poly lactic-co-glycolic acid (PLGA) as biodegradable controlled drug delivery carrier. Polymers (Basel). 2011;3(3):1377-1397.

112. Dhanda DS, Tyagi P, Mirvish SS, Kompella UB. Supercritical fluid technology based large porous celecoxib-PLGA microparticles do not induce pulmonary fibrosis and sustain drug delivery and efficacy for several weeks following a single dose. J Control Release. 2013;168(3):239-250.

113. Petros RA, DeSimone JM. Strategies in the design of nanoparticles for therapeutic applications. Nat Rev Drug Discov. 2010;9(8):615-627.
114. Chu KS, Schorzman AN, Finniss MC, et al. Nanoparticle drug loading as a design parameter to improve docetaxel pharmacokinetics and efficacy. Biomaterials. 2013;34(33):8424-8429.

115. Mahapatro A, Singh DK. Biodegradable nanoparticles are excellent vehicle for site directed in-vivo delivery of drugs and vaccines. J Nanobiotechnology. 2011;9(1):55.

116. Brannon-Peppas L, Blanchette JO. Nanoparticle and targeted systems for cancer therapy. Adv Drug Deliv Rev. 2012;64:206-212.

117. Brewer E, Coleman J, Lowman A. Emerging technologies of polymeric nanoparticles in cancer drug delivery. J Nanomater. 2011;(2011) 408675.

118. Damascelli B, Patelli GL, Lanocita R, et al. A novel intraarterial chemotherapy using paclitaxel in albumin nanoparticles to treat advanced squamous cell carcinoma of the tongue: preliminary findings. AJR Am J Roentgenol. 2003;181(1):253-260.

119. Sulfikkarali N, Krishnakumar N, Manoharan S, Nirmal RM. Chemopreventive efficacy of naringenin-loaded nanoparticles in 7,12dimethylbenz(a)anthracene induced experimental oral carcinogenesis. Pathol Oncol Res. 2013;19(2):287-296.

120. Yu D, Wang A, Huang H, Chen Y. PEG-PBLG nanoparticle-mediated HSV-TK/GCV gene therapy for oral squamous cell carcinoma. Nanomedicine (Lond). 2008;3(6):813-821.

121. Endo K, Ueno T, Kondo S, et al. Tumor-targeted chemotherapy with the nanopolymer-based drug NC-6004 for oral squamous cell carcinoma. Cancer Sci. 2013;104(3):369-374.

122. Li P, Zhou G, Zhu X, et al. Photodynamic therapy with hyperbranched poly(ether-ester) chlorin(e6) nanoparticles on human tongue carcinoma CAL-27 cells. Photodiagnosis Photodyn Ther. 2012;9(1): 76-82.

123. Dos Santos FK, Oyafuso MH, Kiill CP, Daflon-Gremiao MP, Chorilli M. Nanotechnology-based drug delivery systems for treatment of hyperproliferative skin diseases - a review. Curr Nanosci. 2013;9(1):159-167.

124. Ribeiro de Souza AL, Kiill CP, dos Santos FK, et al. Nanotechnologybased drug delivery systems for dermatomycosis treatment. Curr Nanosci. 2012;8(4):512-519.

125. Parveen S, Misra R, Sahoo SK. Nanoparticles: a boon to drug delivery, therapeutics, diagnostics and imaging. Nanomedicine. 2012;8(2): $147-166$

126. Souto EB, Doktorovová S. Chapter 6 - solid lipid nanoparticle formulations pharmacokinetic and biopharmaceutical aspects in drug delivery. Methods Enzymol. 2009;464:105-129.

127. Wissing S, Kayser O, Müller R. Solid lipid nanoparticles for parenteral drug delivery. Adv Drug Deliv Rev. 2004;56(9):1257-1272.

128. Mehnert W, Mäder K. Solid lipid nanoparticles: production, characterization and applications. Adv Drug Deliv Rev. 2001;47(2):165-196.

129. Müller RH, Mäder K, Gohla S. Solid lipid nanoparticles (SLN) for controlled drug delivery - a review of the state of the art. Eur J Pharm Biopharm. 2000;50(1):161-177.

130. Patel M, Souto EB, Singh KK. Advances in brain drug targeting and delivery: limitations and challenges of solid lipid nanoparticles. Expert Opin Drug Deliv. 2013;10(7):889-905.

131. Shi SJ, Zhong ZR, Liu J, Zhang ZR, Sun X, Gong T. Solid lipid nanoparticles loaded with anti-microRNA oligonucleotides (AMOs) for suppression of microRNA-21 functions in human lung cancer cells. Pharm Res. 2012;29(1):97-109.

132. Kakkar V, Singh S, Singla D, Kaur IP. Exploring solid lipid nanoparticles to enhance the oral bioavailability of curcumin. Mol Nutr Food Res. 2011;55(3):495-503.

133. Holpuch AS, Hummel GJ, Tong M, et al. Nanoparticles for local drug delivery to the oral mucosa: proof of principle studies. Pharm Res. 2010;27(7):1224-1236.

134. Battaglia L, Gallarate M. Lipid nanoparticles: state of the art, new preparation methods and challenges in drug delivery. Expert Opin Drug Deliv. 2012;9(5):497-508.

135. Fang JY, Fang CL, Liu CH, Su YH. Lipid nanoparticles as vehicles for topical psoralen delivery: solid lipid nanoparticles (SLN) versus nanostructured lipid carriers (NLC). Eur J Pharm Biopharm. 2008;70(2): 633-640. 
136. Lin YK, Huang ZR, Zhuo RZ, Fang JY. Combination of calcipotriol and methotrexate in nanostructured lipid carriers for topical delivery. Int J Nanomedicine. 2010;5:117-128.

137. Kovacevic A, Savic S, Vuleta G, Müller R, Keck C. Polyhydroxy surfactants for the formulation of lipid nanoparticles (SLN and NLC): effects on size, physical stability and particle matrix structure. Int $J$ Pharm. 2011;406(1-2):163-172.

138. Aditya N, Shim M, Lee I, Lee Y, Im MH, Ko S. Curcumin and genistein coloaded nanostructured lipid carriers: In vitro digestion and antiprostate cancer activity. J Agric Food Chem. 2013;61(8): 1878-1883.

139. Zlotogorski A, Dayan A, Dayan D, Chaushu G, Salo T, Vered M. Nutraceuticals as new treatment approaches for oral cancer - I: curcumin. Oral Oncol. 2013;49(3):187-191.

140. Chinsriwongkul A, Chareanputtakhun P, Ngawhirunpat T, et al. Nanostructured lipid carriers (NLC) for parenteral delivery of an anticancer drug. AAPS Pharm Sci Tech. 2012;13(1):150-158.

141. Wang J, Dai Y, Huang Y, et al. All-trans retinoic acid restores gap junctional intercellular communication between oral cancer cells with upregulation of $\mathrm{Cx} 32$ and $\mathrm{Cx} 43$ expressions in vitro. Med Oral Patol Oral Cir Bucal. 2013;18(4):e569-e577.

142. Liu S1, Zhong SS, Ye DX, Chen WT, Zhang ZY, Deng J. Repression of $\mathrm{G}$ protein-coupled receptor family $\mathrm{C}$ group 5 member $\mathrm{A}$ is associated with pathologic differentiation grade of oral squamous cell carcinoma. J Oral Pathol Med. 2013;42(10):761-768.

143. Liu D, Liu Z, Wang L, Zhang C, Zhang N. Nanostructured lipid carriers as novel carrier for parenteral delivery of docetaxel. Colloids Surf B Biointerfaces. 2011;85(2):262-269.

144. Iida S, Shimada J, Sakagami H. Cytotoxicity induced by docetaxel in human oral squamous cell carcinoma cell lines. In Vivo. 2013;27(3): 321-332.

145. Zhang T, Chen J, Zhang Y, Shen Q, Pan W. Characterization and evaluation of nanostructured lipid carrier as a vehicle for oral delivery of etoposide. J Pharm Sci. 2011;43(3):174-179.

146. Mishima K, Inoue K, Hayashi Y. Overexpression of extracellularsignal regulated kinases on oral squamous cell carcinoma. Oral Oncol. 2002;38(5):468-474.

147. Liu L, Tang Y, Gao C, et al. Characterization and biodistribution in vivo of quercetin-loaded cationic nanostructured lipid carriers. Colloids Surf B Biointerfaces. 2014;115:125-131.

148. Kang B, Mackey MA, El-Sayed MA. Nuclear targeting of gold nanoparticles in cancer cells induces DNA damage, causing cytokinesis arrest and apoptosis. J Am Chem Soc. 2010;132(5):1517-1519.

149. Wang F, Wang YC, Dou S, Xiong MH, Sun TM, Wang J. Doxorubicintethered responsive gold nanoparticles facilitate intracellular drug delivery for overcoming multidrug resistance in cancer cells. ACS Nano. 2011;5(5):3679-3692.

150. El-Sayed IH, Huang X, El-Sayed MA. Surface plasmon resonance scattering and absorption of anti-EGFR antibody conjugated gold nanoparticles in cancer diagnostics: applications in oral cancer. Nano Lett. 2005;5(5):829-834.

151. Kah JC, Kho KW, Lee CG, et al. Early diagnosis of oral cancer based on the surface plasmon resonance of gold nanoparticles. Int J Nanomedicine. 2007;2(4):785-798.

152. Afifi MM, El Sheikh SM, Abdelsalam MM, et al. Therapeutic efficacy of plasmonic photothermal nanoparticles in hamster buccal pouch carcinoma. Oral Surg Oral Med Oral Pathol Oral Radiol. 2013;115(6): 743-751.

153. Mezei M, Gulasekharam V. Liposomes - a selective drug delivery system for the topical route of administration. Lotion dosage form. Life Sci. 1980;26(18):1473-1477.

154. Lian T, Ho RJ. Trends and developments in liposome drug delivery systems. J Pharm Sci. 2001;90(6):667-680.

155. Allen TM, Cullis PR. Drug delivery systems: entering the mainstream. Science. 2004;303(5665):1818-1822.

156. Pedroso de Lima MC, Simões S, Pires P, Faneca H, Düzgüneş N. Cationic lipid-DNA complexes in gene delivery: from biophysics to biological applications. Adv Drug Deliv Rev. 2001;47(2):277-294.
157. Konopka K, Fallah B, Monzon-Duller J, Overlid N, Düzgünes N. Serum-resistant gene transfer to oral cancer cells by Metafectene and GeneJammer: application to HSV-tk/ganciclovir-mediated cytotoxicity. Cell Mol Biol Lett. 2005;10(3):455-470.

158. Figueiró Longo JP, Muehlmann LA, Velloso NV, et al. Effects of photodynamic therapy mediated by liposomal aluminum-phthalocyanine chloride on chemically induced tongue tumors. Chemotherapy. 2012;1:103.

159. Velloso NV, Muehlmann LA, Longo JPF, et al. Aluminum-phthalocyanine chloride-based photodynamic therapy inhibits PI3K/Akt/Mtor pathway in oral squamous cell carcinoma cells in vitro. Chemotherapy. 2012;1:107.

160. Bahram M, Hoseinzadeh F, Farhadi K, Saadat M, Najafi-Moghaddam P, Afkhami A. Synthesis of gold nanoparticles using $\mathrm{pH}$-sensitive hydrogel and its application for colorimetric determination of acetaminophen, ascorbic acid and folic acid. Colloids Surf A Physicochem Eng Asp. 2014;441:517-524.

161. Giri TK, Thakur A, Alexander A, Ajazuddin, Badwaik H, Tripathi DK. Modified chitosan hydrogels as drug delivery and tissue engineering systems: present status and applications. Acta Pharm Sin B. 2012;2(5): 439-449.

162. Ruel-Gariépy E, Shive M, Bichara A, et al. A thermosensitive chitosanbased hydrogel for the local delivery of paclitaxel. Eur J Pharm Biopharm. 2004;57(1):53-63.

163. Obara K, Ishihara M, Ozeki Y, et al. Controlled release of paclitaxel from photocrosslinked chitosan hydrogels and its subsequent effect on subcutaneous tumor growth in mice. J Control Release. 2005;110(1): 79-89.

164. Konishi M, Tabata Y, Kariya M, et al. In vivo anti-tumor effect through the controlled release of cisplatin from biodegradable gelatin hydrogel. J Control Release. 2003;92(3):301-313.

165. Gurski LA, Jha AK, Zhang C, Jia X, Farach-Carson MC. Hyaluronic acid-based hydrogels as $3 \mathrm{D}$ matrices for in vitro evaluation of chemotherapeutic drugs using poorly adherent prostate cancer cells. Biomaterials. 2009;30(30):6076-6085.

166. Gao Y, Ren F, Ding B, et al. A thermo-sensitive PLGA-PEG-PLGA hydrogel for sustained release of docetaxel. J Drug Target. 2011;19(7): 516-527.

167. Hao T, Li Z, Qiao M, Fan Q, Zhang N, Chen D. [Preparation of docetaxel hydrogels for subcutaneous injection and their release profile in vitro]. Chinese Pharmaceutical Journal. 2009;24: 15. Chinese.

168. Shaker DS, Ghorab MK, Klingner A, Teiama MS. In-situ injectable thermosensitive gel based on poloxamer as a new carrier for tamoxifen citrate. Int J Pharm Pharm Sci. 2013;5(Suppl 4):429-437.

169. Konishi M, Tabata Y, Kariya M, et al. In vivo anti-tumor effect of dual release of cisplatin and adriamycin from biodegradable gelatin hydrogel. J Control Release. 2005;103(1):7-19.

170. Deurloo MM, Kop W, van Tellingen O, Bartelink H, Begg A. Intratumoural administration of cisplatin in slow-release devices: II. Pharmacokinetics and intratumoural distribution. Cancer Chemother Pharmacol. 1991;27(5):347-353.

171. Tauro JR, Gemeinhart RA. Extracellular protease activation of chemotherapeutics from hydrogel matrices: a new paradigm for local chemotherapy. Mol Pharm. 2005;2(5):435-438.

172. Casolaro M, Cini R, Del Bello B, Ferrali M, Maellaro E. Cisplatin/ hydrogel complex in cancer therapy. Biomacromolecules. 2009;10(4): 944-949.

173. Fang L, Wang $\mathrm{H}$, Zhou L, Yu D. FOXO3a reactivation mediates the synergistic cytotoxic effects of rapamycin and cisplatin in oral squamous cell carcinoma cells. Toxicol Appl Pharmacol. 2011; 251(1):8-15.

174. Moura MJ, Gil MH, Figueiredo MM. Delivery of cisplatin from thermosensitive co-cross-linked chitosan hydrogels. Eur Polym J. 2013; 49(9):2504-2510.

175. Salamat-Miller N, Chittchang M, Johnston TP. The use of mucoadhesive polymers in buccal drug delivery. Adv Drug Deliv Rev. 2005; 57(11):1666-1691. 
176. Emoto S, Yamaguchi H, Kamei T, et al. Intraperitoneal administration of cisplatin via an in situ cross-linkable hyaluronic acid-based hydrogel for peritoneal dissemination of gastric cancer. Surg Today. 2014;44(5):919-926.

177. Li J, Gong C, Feng X, et al. Biodegradable thermosensitive hydrogel for SAHA and DDP delivery: therapeutic effects on oral squamous cell carcinoma xenografts. PloS One. 2012;7(4):e33860.

178. Formariz TP, Urban MCC, da Silva Júnior AA, Gremião MPD, de Oliveira AG. Microemulsões e fases líquidas cristalinas como sistemas de liberação de fármacos [Microemulsion and liquid crystals as drug delivery systems]. Revista Brasileira de Ciências Farmacêuticas. 2005;41:301-313. Portuguese.

179. Chorilli M, Prestes PS, Rigon RB, Leonardi GR, Chiavacci LA, Scarpa MV. Desenvolvimento de sistemas líquido-cristalinos empregando silicone fluido de co-polímero glicol e poliéter funcional siloxano [Development of liquid-crystalline systems using silicon glycol copolymer and polyether functional siloxane]. Quim Nova. 2009;32:1036-1040. Portuguese.

180. Prestes PS, Chorilli M, Chiavacci LA, Scarpa MV, Leonardi GR. Physicochemical characterization and rheological behavior evaluation of the liquid crystalline mesophases developed with different silicones. J Dispers Sci Technol. 2009;31(1):117-123.

181. Manaia EB, Kaminski RCK, Soares CP, et al. Liquid crystalline formulations containing modified surface $\mathrm{TiO}_{2}$ nanoparticles obtained by sol-gel process. J Solgel Sci Technol. 2012;63(2):251-257.

182. de Castro Santana R, Fasolin LH, da Cunha RL. Effects of a cosurfactant on the shear-dependent structures of systems composed of biocompatible ingredients. Colloids Surf A Physicochem Eng Asp. 2012;398:54-63.

183. Ezrahi S, Aserin A, Garti N. Aggregation behavior in one-phase (Winsor IV) microemulsion systems. In: Kumar P, Mittal KL, editors. Handbook of Microemulsion Science and Technology. New York, NY: Marcel Dekker, Inc.; 1999:185-246.

184. Hosmer JM, Shin SH, Nornoo A, Zheng H, Lopes LB. Influence of internal structure and composition of liquid crystalline phases on topical delivery of paclitaxel. J Pharm Sci. 2011;100(4):1444-1455.

185. Myoung H, Hong SD, Kim YY, Hong SP, Kim MJ. Evaluation of the anti-tumor and anti-angiogenic effect of paclitaxel and thalidomide on the xenotransplanted oral squamous cell carcinoma. Cancer Lett 2001;163(2):191-200.

186. Kioi M, Shimamura T, Nakashima H, et al. IL-13 cytotoxin has potent antitumor activity and synergizes with paclitaxel in a mouse model of oral squamous cell carcinoma. Int J Cancer. 2009;124(6): 1440-1448

187. Eckardt A, Sinikovic B, Hofele C, Bremer M, Reuter C. Preoperative paclitaxel/carboplatin radiochemotherapy for stage III/IV resectable oral and oropharyngeal cancer: seven-year follow-up of a phase II trial. Oncology. 2008;73(3-4):198-203.

188. Cheung MC, Pantanowitz L, Dezube BJ. AIDS-related malignancies: emerging challenges in the era of highly active antiretroviral therapy. Oncologist. 2005;10(6):412-426.

189. Ferguson T, Wilcken N, Vagg R, Ghersi D, Nowak A. Taxanes for adjuvant treatment of early breast cancer. Cochrane Database Syst Rev. 2007;(4):CD004421.
190. Rizwan S, Assmus D, Boehnke A, et al. Preparation of phytantriol cubosomes by solvent precursor dilution for the delivery of protein vaccines. Eur J Pharm Biopharm. 2011;79(1):15-22.

191. Zeng N, Hu Q, Liu Z, et al. Preparation and characterization of paclitaxel-loaded DSPE-PEG-liquid crystalline nanoparticles (LCNPs) for improved bioavailability. Int J Pharm. 2012;424(1-2):58-66.

192. Martins MRFM, Veiga F. Promotores de permeação para a liberação transdérmica de fármacos: uma nova aplicação para as ciclodextrinas [Permeation enhancers in transdermal drug delivery systems: a new application of cyclodextrins]. Revista Brasileira de Ciências Farmacêuticas. 2002;38(1):33-54. Portuguese.

193. Li S, Purdy WC. Cyclodextrins and their applications in analytical chemistry. Chem Rev. 1992;92(6):1457-1470.

194. Zhang J, Ma PX. Cyclodextrin-based supramolecular systems for drug delivery: recent progress and future perspective. Adv Drug Deliv Rev. 2013;65(9):1215-1233.

195. Concheiro A, Alvarez-Lorenzo C. Chemically cross-linked and grafted cyclodextrin hydrogels: from nanostructures to drug-eluting medical devices. Adv Drug Deliv Rev. 2013;65(9):1188-1203.

196. Szejtli J, Osa T, editors. Comprehensive Supramolecular Chemistry. Vol 3: Cyclodextrins. Oxford: Elsevier Science Ltd; 1996. Szejtli J. Introduction and general overview of cyclodextrin chemistry. Chem Rev. 1996;98(5):1743-1754.

197. Veiga FJB. Complexos de Inclusão com Ciclodextrinas Hidrófilas: Caracterização Físico-Química e Biofarmacêutica [Inclusion complexes with hydrophilic cyclodextrins: Physico-chemical and biopharmaceutical characterization] [doctoral thesis]. Coimbra: University of Coimbra; 1996. Portuguese.

198. Sallas F, Darcy R. Amphiphilic cyclodextrins - advances in synthesis and supramolecular chemistry. European J Org Chem. 2008;(6): 957-969.

199. Hirayama F, Uekama K. Cyclodextrin-based controlled drug release system. Adv Drug Deliv Rev. 1999;36(1):125-141.

200. Ramineni SK, Cunningham LL, Dziubla TD, Puleo DA. Development of imiquimod-loaded mucoadhesive films for oral dysplasia. J Pharm Sci. 2013;102(2):593-603.

201. Jing J, Szarpak-Jankowska A, Guillot R, Pignot-Paintrand I, Picart C, Auzély-Velty R. Cyclodextrin/paclitaxel complex in biodegradable capsules for breast cancer treatment. Chem Mater. 2013;25(19): 3867-3873.

202. He H, Chen S, Zhou J, et al. Cyclodextrin-derived pH-responsive nanoparticles for delivery of paclitaxel. Biomaterials. 2013;34(21): 5344-5358

203. Eifer AC, Thaxton CS. Nanoparticle therapeutics: FDA approval, clinical trials, regulatory pathways, and case study. In: Hurst SJ, editor. Biomedical Nanotechnology: Methods and Protocols. New York: Humana Press; 2011:235-338.

204. Yang K, Wen Y, Wang C. [Clinical application of anticancer nanoparticles targeting metastasis foci of cervical lymph nodes in patients with oral carcinoma]. Hua Xi Kou Qiang Yi Xue Za Zhi. 2003;21(6) 447-450. Chinese.

205. Hull LC, Farrell D, Grodzinski P. Highlights of recent developments and trends in cancer nanotechnology research-View from NCI Alliance for Nanotechnology in Cancer. Biotechnol Adv. Epub 12 August, 2013.
International Journal of Nanomedicine

\section{Publish your work in this journal}

The International Journal of Nanomedicine is an international, peerreviewed journal focusing on the application of nanotechnology in diagnostics, therapeutics, and drug delivery systems throughout the biomedical field. This journal is indexed on PubMed Central,

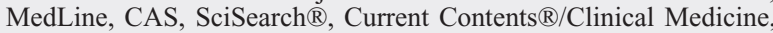

\section{Dovepress}

Journal Citation Reports/Science Edition, EMBase, Scopus and the Elsevier Bibliographic databases. The manuscript management system is completely online and includes a very quick and fair peer-review system, which is all easy to use. Visit http://www.dovepress.com/ testimonials.php to read real quotes from published authors. 